\title{
IN THEIR SHOES: EXPLORING THE SOCIAL EXPERIENCES OF BLACK MALE POLICE OFFICERS IN CANADA.
}

by

Anthony Lawrence, BSW, Ryerson University, 2017

\author{
An MRP \\ presented to Ryerson University \\ in partial fulfillment of the \\ requirements for the degree of \\ Master of Social Work \\ in the Program of \\ Social Work
}

Toronto, Ontario, Canada, 2017

(C) Anthony Lawrence 2017 


\section{AUTHOR'S DECLARATION FOR ELECTRONIC SUBMISSION OF A MRP}

I hereby declare that I am the sole author of this MRP. This is a true copy of the MRP, including any required final revisions.

I authorize Ryerson University to lend this MRP to other institutions or individuals for the purpose of scholarly research

I further authorize Ryerson University to reproduce this MRP by photocopying or by other means, in total or in part, at the request of other institutions or individuals for the purpose of scholarly research.

I understand that my MRP may be made electronically available to the public. 


\begin{abstract}
In their shoes: The social experiences of Black male police officers in Canada.

Master of Social Work, 2017

Anthony Lawrence

Program of Social Work, Ryerson University
\end{abstract}

This qualitative research study presents a critical analysis of race and policing by examining the experiences of four Black male police officers in Canada. This study seeks to understand the essence of these experiences and understand the reality of what it means to be a Black male police officer. Included are the results of qualitative interviews with these police officers, using critical race theory as the theoretical framework to explain participants' experiences as police officers. The themes that emerged from the interviews were the following: the glass ceiling for Black police officers; issues of identity and belonging; negative stereotyping; and future recommendations. Given that this group belongs to both a profession which exhibits inherent racial bias, in the form of over-surveillance and the use of excessive (and even lethal) force against racialized minorities, as well as belonging to the very minority community targeted by the police, it is imperative that we explore and understand the unique tensions black officers experience. 


\section{TABLE OF CONTENTS}

CHAPTER 1: INTRODUCTION Page \# 1-5

CHAPTER 2: LITERATURE REVIEW Page \# 6-17

CHAPTER 3: THEORETICAL AND CONCEPTUAL FRAMEWORW

Page \# 18-24

CHAPTER 4. METHODOLOGY .Page \# 25-30

CHAPTER 5 : FINDINGS AND ANALYSIS . Page \# 31-53

CHAPTER 6. IMPLICATIONS AND CONCLUSION. Page \# 54-59

APPENDICES Page \# 60-68

REFERENCES .Page \# 69-75 


\section{LIST OF APPENDICES}

Appendix A - VERBAL RECRUITMENT SCRIPT $\ldots \ldots \ldots \ldots \ldots \ldots \ldots \ldots \ldots \ldots \ldots \ldots . . . \ldots$. $\ldots$ age \# 60

Appendix B - INTERVIEW GUIDE......................................Page \# 61-62

Appendix C - CONSENT FORM......................................Page \# 63-67

Appendix D - POST INTERVIEW RESOURCE SHEET ...........................Page \# 68 


\section{CHAPTER 1. INTRODUCTION}

In recent decades, visible minority communities have reported increasing problems with police interactions in Canada. Despite increasing claims of police mistreatment, discrimination and violence against visible minorities, policing institutions fail to respond appropriately to such claims. Particularly, the claims for social justice from residents of predominately Black communities continue to fall on deaf ears (Walcott, 2003). Grieve and French (2000) argue that racialized communities must fight to be heard by policing institutions that are not interested in listening or understanding. Moreover, Walcott (2003) asserts that there is a misconception that Canada is a nation of equality, where everybody belongs, but in fact, racialized people are often viewed as non-white others, outside of what it means to be an authentic Canadian. By perceiving visible minorities as falling outside of the nation, it follows that their concerns around policing issues may not be taken seriously. In other words, the police have taken on a role as agents, through whom the dominant culture enforces its positon (Walcott, 2003).

In recent years, the social tension between police officers and visible minority communities has been intensifying in Canada and the United States. Members of AfricanAmerican communities have reported increasing experiences of being targeted and racially stereotyped by police officers (Jayewardene \& Talbot, 1990). The Guardian News in the United States of America reports that although Black people make up only $6 \%$ of the population, $25.5 \%$ of victims of police violence are Black (Kennedy and Hansford, 2016). Similarly, in Canada, Black people are three times more likely to experience racial stereotyping compared to whites (Wortley \& Owusu-Bempah, 2011). While these statistics invariably point to fact that Black people are disproportionately more likely to be over-policed than their non-Black counterparts, recurring news accounts in the media also portray a vivid picture of racial bias amongst police 
officers. News reports and videos capturing fatal police violence against Black communities are becoming an unfortunate and frequent reoccurrence in the media throughout Canada and the United States of America.

The purpose of exploring this issue is that Black male police officers are in a unique situation; belonging to both the police force and as members of visible minority communities. It follows that this unique social experience of being both Black and a police officer may result in increased pressures to navigate their lives between both groups. In this regard, it can be argued that when Black male police officers take off their uniforms, they are no longer perceived as police; instead they may be viewed by a uniformed officer simply as a Black body out of place or not belonging (Owusu-Bempah, 2014). Additionally, even when Black officers have their uniforms on, they may still not be regarded as belonging within the force by their white colleagues. The police uniform does not automatically equate to equality within the police force (Owusu-Bempah, 2014). Due to the colour of their skin, which supersedes the privilege of their profession, Black police officers have their own experiences with racial profiling or know members of their family, friends or community that have had negative experiences with the police (Jayewardene \& Talbot, 1990).

\section{Locating Identity within the Concept of 'the Stranger'}

In the context of socio-political climates of homogenous policing cultures, the concept of the 'stranger' is directly linked to danger within purified spaces (Ahmed, 2000; Thobani, 2007). Anyone that does not represent the dominant group, especially regarding their race, can be considered a danger or stranger out of place. The relationship between strangeness and not belonging in such purified spaces is especially apparent in the case of visible minorities and immigrants (Ahmed, 2000). The challenge for racialized groups to be welcomed in a community 
in which they a purported to not belong is best understood in the backdrop of the concept that the street is a living form of community (Ahmed, 2000). Essentially, Ahmed argues that a street can represent a community and that only those who belong to that community should be walking on that street. This directly impacts the way that police interact with racialized bodies that they see as not belonging in certain (white) spaces.

As a person who identifies as Black, I have had negative interactions with the police due to the colour of my skin. An occurrence where I felt targeted based on my race solidified my interest in examining the experiences of racialized police officers. In this incident, there were two police officers involved: one white and one Black. The white officer said that my front window tint was too dark. I told the officer that it is not too dark and I have the paperwork from the place where I got it tinted to show it was the legal limit $35 \%$ percent. The white officer got upset because I did not agree with him and he became verbally aggressive toward me. He told me that he would write down my license plate and give me two days to change my window tint and come to his police division to show him that it was done, and if I did not, I would be issued a ticket. Again, I offered to show him the paper which indicated that my car was tinted to the legal limit, but he refused to see it. In this case, getting pulled over was not what shocked me about this situation (as I feel this is the norm for most Black men).

What surprised me most about the situation was when the white officer asked me: "Why do all of you Black guys keep a bible on the top of your back seat? You guys are not fooling anyone." The Black officer remained silent during this whole interaction, but I could see in his face that he was uncomfortable with the situation. In this regard, race is at play in two ways: one being that I was evidently stereotyped, and the other being that a Black officer may have felt vulnerable to challenge the actions of his white colleague. It is also possible that the silence of 
the Black officer was not an implicit endorsement of the white officer's discrimination toward me; instead, the Black officer may have strategically chosen to be silent in the face of this conflict to preserve his relationship with his colleague.

This event, taken together with other events not mentioned here, sparked my interest in this research topic of exploring the lived realities of Black officers and their experiences in the police force. The purpose of this qualitative study is to explore the experiences of Black male police officers in Canada and to understand the essence of the experiences of these police officers. The aim of my study is to interview several individuals who have shared the experience of being a Black male working in a police institution in Canada.

There are two research questions that guide this research study: First, I am interested in examining the views, perceptions and feelings of Black male police officers. The dynamic I seek to explore is the inherent tension that Black officers face when members of the police force are disproportionately stereotyping members of their own race. Second, I want to explore the experiences of racism that Black officers feel within the policing institution and in their daily lives at work. By exploring these research questions, I seek to demonstrate how Black male police officers view their experiences of navigating their lives between Black communities and the policing institutions these communities have been protesting for years.

The scope of this major research paper (MRP) pertains to the daily, lived realities of Black male police officers. It is important to recognize that by choosing one particular social group to focus on, my research is inherently limited. It follows that the experiences of innumerable social groups were not addressed in the scope of my MRP. In order to accurately address the intersectionality of social constructs such as race, gender and social occupation, it is necessary to identify the variables and factors that have invariably influenced and impacted the 
results of my research. I recognize that the conclusions derived from my qualitative research are not generalizable to a larger population.

While it is the intention of this MRP to cast light on the various experiences of racialized groups within the police force, given the restrictions on resources, with respect to time and page limits, I chose to focus on the one group of Black males within policing. It is my intention in future research endeavours to expand upon this research to include an intersectional analysis with respect to gender, sexual orientation, socio-economic status and other forms of identity that influence the daily lives of racialized police officers. An important area to expand upon in future research would be to examine the experience of Black female police officers. Addressing the intersectionality of issues faced by female police officers would be invaluable to ensuring critical, holistic, and multi-faceted research. Moreover, it would be imperative to use a critical race theory lens to examine the daily lived realities of members of racialized LBGTQ communities within the police force. The various social groups I could not study in my current MRP point the way to future research endeavours which would encapsulate and include more varied members of marginalized communities.

In addition to the limitations with respect to the social groups that I could not include, my research is also limited with respect to research methods due to time constraints. For instance, I employed the research method of interviews and data analysis. In future efforts, where more time could be dedicated to my research topic, I would consider relying on participant observation to glean greater insight into the ways in which racialized police officers are treated at work. If permitted, I would consider ride-alongs with police officers to observe and take notes about the ways in which racialized police officers interact with the community, and how the community and their colleagues interact with them. 


\section{CHAPTER 2. LITERATURE REVIEW}

\section{Over Surveillance of Racialized Communities}

In recent decades, members of visible minority communities have been experiencing intensified and increasing social control and oversurveillance by the police force. At an alarming rate, racialized communities experience a consistently high and saturated police presence, which garners both fear and tension amongst individuals in these communities (Brewer \& Hietzeg, 2008). Specifically, in Canada, the Black population experiences disproportionate rates of oversurveillance in the form of being arbitrarily stopped and searched. This social control is exacerbated by the fact that police-carding, the practice of monitoring individuals and entering their personal details in a police database, has the invariable effect of targeting minorities (Brewer \& Hietzeg, 2008).

This oversurveillance of racialized people has been called the 'New Plantation' where Blacks are purposely targeted and incarcerated as a form of social control (Brewer \& Hietzeg, 2008). Although slavery may no longer exist, new forms of systemic racism have emerged. Thus, we are seeing an enhanced police presence in poor neighborhoods and communities of colour; racial profiling; increased rates of adult certification for juvenile offenders; mandatory minimum and three strike sentencing (Brewer \& Hietzeg, 2008). The racialization of crime has negative effects on Black men and women who continue to be treated like suspects by the police whether they committed a crime or not. Thus, being Black becomes synonymous with being deviant (Sewell, Horsford, Coleman \& Watkins, 2016).

In contrast to the views advanced by critical race theorists, Kelling and Coles (1996) in their book titled "Fixing Broken Windows", argue that the reason racialized communities experience oversurveillance is because they commit more crimes than whites. They advance 
evidence suggesting that racialized people have higher rates of seizures of weapons and drugs, which justifies aggressive policing. Kelling and Coles (1996) argue "that the use of aggressive policing tactics toward marginal populations, will allow order to be restored, thereby reducing crime and allowing good citizens to emerge" (p. 36).

The theory put forth by Kellings and Coles (1996) fails to address the underlying systemic racism that leads to social problems like poverty, racism, unemployment, hunger, subordination, and the impacts of marginalization experienced by these communities (National Institute of Justice, 2011). A study by the National Institute of Justice, in direct contrast with Kelling and Coles' book, suggests that poverty is the most important factor with respect to the functions of a community, and that oversurveillance and excessive police strategies do more harm than benefit to these communities (National Institute of Justice, 2011).

\section{Policing Practices and Traffic Stops}

A method used by the police to monitor visible minorities and the communities they reside in is traffic enforcement and traffic stops. The unfortunate reality is that the use of traffic control by the police is the inherent racial profiling employed by police officers during these traffic stops (Novak \& Chamlin, 2012). Racial profiling is defined as the assumption that someone is a suspect or that they have committed an offense because of their race, culture or ethnicity (Novak \& Chamlin, 2012). An example of racial profiling is the assumption that because there is a Black male driving a nice car, then that car must be stolen. Police assumptions about race have real and substantial implications, which play out in the lives of visible minorities every day.

A 2012 study exploring the racial threat and suspicion of police behaviour concluded that the more visible minorities that live in a community, then the more likely they are to be stopped 
by the police (Novak \& Chamlin, 2012). Even when Blacks are not in predominately racialized communities, they are still more likely to be stopped. There is the assumption that when Black people are in predominately white communities, his or her race does not match with the racial composition of that community or neighborhood, thus making them a threat or suspicious body (Brown, 1981). Novak and Chamlin (2012) refer to this phenomenon as 'race out of place', which leads officers to believe that Blacks do not belong in those spaces and as a response, Black people experience getting stopped by police, searched and issued citations for no reason other than being Black (Ibe, Ochie, \& Obiyan, 2012).

The concept of 'race out of place' contributes to the fact that Blacks are disproportionately pulled over by the police compared to whites. The term "driving while Black" comes from the ongoing experiences of Blacks who have been stopped by traffic enforcement for no legitimate reason. Black people who have been unlawfully stopped acknowledge how uncomfortable they felt and that feeling harassed by the police was not an uncommon occurrence in their daily lives (Ibe, Ochie \& Obiyan, 2012). In this regard, criminologist Volpp (2002) argues that when a white person is pulled over, it is assumed that this was an individual behaviour and not one that can be generalized to the entire white population. However, when a Black person is pulled over, it is assumed that they have the prototypical qualities of a particular group, with negative connotations attached to them (Volpp, 2002).

\section{Policing Practices: Carding}

Like the Stop and Frisk policy in New York, Toronto, had its own method of stop and frisk called Carding, which refers to randomized police checks. Lawyer and social justice activist, Knia Singh proposes: 
"There is no difference at all between carding and profiling. What we keep calling carding is the documentation of information to create this database, but the real problem for African-Canadians is the initial stop, which is racial profiling. When you are being stopped based on no other reason except your skin colour, that is arbitrary detention" (Maclellan, 2015).

Singh articulates the argument and complaint that many racialized people have expressed about being targeted by police because of their skin colour. This targeting of skin colour goes back to the days of slavery. Throughout slavery, slave passes and freedom papers were part of a system that was set up to restrict and criminalize Black mobility and autonomy, and have white men patrol the everyday movements of Black people. Carding is a continued practice of restricting Black mobility and is used as a method of social control (Jones-Rogers, 2013). Canadian Judge Harry Laforme reiterated the problems with carding in Canada. "This kind of daily tracking of the whereabouts of persons including many innocent law-abiding persons has an aspect to it that reminds me of former government regimes that I am certain all of us would prefer not to replicate" (Stuart \& Tanovich, 2014). Moreover, Wagner (2009) explains that the same people who were responsible for enforcing slave laws were the police, who enforced curfews and randomly stopped slaves they found on the street. The same concerns with carding have been pointed out by many community activists who have experienced random stops by the police.

The hyper-surveillance of Blacks invariably hinder relationships between police and Black communities. A 2008 study on citizen attitudes toward police in Canada found that visible minorities hold negative views of the police, with race being the strongest factor predicting attitudes toward police (O’Connor, 2008). Similarly, a 2010 U.S. study reiterated the same findings; African Americans reported unfavourable attitudes toward the police because of their 
experiences with them (Lai \& Zhao, 2010). In response to these troubling observations, O'Connor (2008) asks us to question whether the police are making an active attempt to work with these groups to improve relations. O'Connor (2008) goes on to say that if there is nothing being done to improve the relationship, then the fundamental legitimacy of the policing institution must be called into question.

\section{Violence and Excessive Force}

The monitoring and oversurveillance of minority communities is inherently problematic as it has the consequence of promoting violence and excessive force by the police against these communities. The persistent social control exerted over the Black population not only perpetuates racial bias, it also creates a social environment which is conducive to excessive force against minority community members (Micucci \& Gomme, 2005). Police brutality, fueled by neoliberal racist ideologies, is an unfortunate, but increasingly common reoccurrence in modern society. Members of Black communities often experience heightened aggression and violence from police officers. The turmoil of the current social landscape has created a condition of uncertainty, fear and sharp tension with respect to the actions of police officers and how far they can go (Micucci \& Gomme, 2005). The recent cases of Eric Garner, Sammy Yatim and Abdi Abdirahman, signal the dangerous and unpredictable behaviour of police officers during altercations with minorities.

Micucci and Gomme (2005) explain that when an officer uses too much force they are sometimes told to calm down from fellow police officers, but when officers use too little force they are perceived as weak and can be subject to reprimand and gossip from their fellow officers. Thus, an officer may engage in excessive force to conform to police subculture and demonstrate to fellow officers that they are to be considered a 'tough and real' police officer. A national 
survey of police officers found that twenty percent (20\%) of officers engage in excessive force when they feel they are being verbally disrespected (Carmichael \& Kent, 2014). However, a large shortcoming of this survey is that it does not account for the pervasive 'code of silence' evident in the police force. This refers to the fact that when officers engage in excessive force, there is a code of silence within the police force that suggests police loyalty to one another is more important than the safety of citizens (Micucci \& Gomme, 2005).

A 2014 study on police use of excessive force in minority communities found that the police implemented greater coercive control strategies in areas with high concentration of Black people. The reason being is that officers often directly associate predominately Black communities with criminality, justifying their use of excessive force strategies (Smith \& Holmes, 2014). In this regard, many police officers view excessive force as a normal part of their job. What is even more problematic is that excessive force may be used to protect the interest of the dominant group and help maintain existing social arrangements which purposely impact visible minorities (Smith \& Holmes, 2014). Smith and Holmes (2014) assert that the police learn to associate these communities with criminality, danger, and challenges to their authority (p. 98).

\section{Police Shootings and Fatalities}

The danger of the commonly used tactics of aggressive and excessive force by police officers against Black communities is the culmination into citizen fatalities at the hands of police. A Canadian study examined police shootings over a 15 year period in Canada and concluded that cities with more visible minorities have more police fatalities. For example, in Toronto and Montreal, during a three year period fifty-percent (50\%) of the people killed by the police were Black, but Black people made up less than five-percent (5\%) of both Toronto and Montreal (Carmichael \& Kent, 2015, p. 713). Studies across Canada have come to similar 
conclusions providing more evidence that police use higher rates of lethal force toward visible minorities.

In 2015, 102 unarmed Black people were killed in the U.S. In Canada, it is hard to obtain similar statistics because there are no race based statistics on fatal shootings by the police. In response to the absence of reliable evidence with respect to police violence, the Toronto Star (Canada's largest daily newspaper) conducted its own investigation to gather race related statistics. They used the dates of fatal shootings and matched them up with the names of the SIU investigation reports and concluded that thirty-five percent $(35 \%)$ of fatal shootings involved a Black person, but Black people only made up $9 \%$ of the population (Gillis, 2015). Additionally, Scot Wortley conducted his own study which concluded that between the years 2000 and 2006, $66 \%$ of fatal police shootings involved Black people, although Black people made up $6.7 \%$ of the population (Gillis, 2015).

A modern day example of police excessive force is the case of Sammy Yatim, an 18 year old visible minority who was shot by the police. The incident, which was caught on video, led to mass protests against police brutality across Canada. The video indicates that the police were quick to draw for the gun, rather than attempt to deescalate the situation. Additionally, witnesses of a 2016 killing by the Ottawa police of a Black Somalian man, Abdi Abdirahman, indicate that the police in this case also used extreme and excessive force, which resulted in the death Abdi. Abdi was continuously kicked and punched in his head by the police officers. What both cases demonstrate is the unfortunate reality that police officers have turned to using aggressive and fatal force against those they view as threats, instead of using an opportunity to deescalate the situation. Both cases have resulted in mass protests and sparked outrage among Canadians with respect to the consistent failure of police to deescalate instead of shoot. (Nease \& Kupfer, 2016). 
Unfortunately, police shootings are becoming a far too common experience for Black bodies in Canada.

Despite the overwhelming evidence and statistics indicating that the police are more likely to use excessive or even lethal force amongst minority groups, critics have proposed an argument which suggests the opposite to be true. A study by James, James and Vila (2016) discusses the reverse racism effect. They concluded that despite clear bias against Black suspects by the police, their study demonstrates that the police are less likely to shoot Black suspects compared to whites. They used a laboratory controlled setting with high definition video scenarios to see how officers responded to Black and white suspects. This simulation found that officers were more likely to shoot white suspects.

While this information offers an interesting and alternative narrative, this research cannot serve as a reliable source of information with respect to police bias due to the inherent shortcomings of the study. The biggest shortcoming with this finding is that the research participants knew they were being viewed and could have easily changed their behaviour to avoid appearing racially biased. The controlled environment of a laboratory is an unrealistic representation of how these officers may respond to Black and white suspects on the job compared to how they responded to these video scenarios. Despite the findings of this study, there have been countless studies and academic research indicating that bias against Blacks does lead to increased killings of Black people (Carmichael \& Kent, 2015). While the conclusions of the James et al. (2016) study may be unreliable, the benefit of such a study is that it reflects the importance and the need to study both the culture and behavioural patterns of police officers. It is therefore imperative to ensure that we continue to examine the behaviours and actions of police 
officers, even in simulated settings, to better understand the policing culture and attitudes under which they operate.

\section{Police Institution: Organization and Subculture}

Systemic racial bias, discrimination and violence against minorities are perpetuated and sustained through the inherent racism built in the police institution. The policing subculture creates an exclusionary environment which rewards conformity and discourages deviation (Gould, 2000). Competitive displays of masculinity and aggression against the "other" are manifested and represented in the police work environment as a form of 'White Brotherhood.' A dominant theme emerging from a 2000 study, conducted using focus-group interviews of visible minority police officers, found that these officers had great difficultly fitting in socially with the Caucasian male culture of police organizations which constitutes the 'old boys' network (Gould, 2000, p. 68).

In addition to the entrenched 'old boys' network reflecting a dominant white male hegemony, racial bias inherent in the policing organization is also supported through recruiting and training tactics. For instance, Jaccoud and Felices (1999) state that police officers are conditioned to display aggressive behaviour and encouraged to use force against those perceived as threats. The problem with using aggressive force against those perceived to be criminal is that most often, the criminal 'other' are Black and minority groups. Accordingly, Micucci and Gomme (2005) suggest, "the police subculture is characterized by suspiciousness, cynicism, and clannishness" (p. 489).

The hostile environment created by a lack of racial diversity in the police force can be the reason why Black police officers feel pressure to conform to a problematic police culture and to avoid backlash (Jain, Singh \& Agocs, 2000). A longitudinal study conducted by Gould (2000) 
highlights the difficulties of Black police officers who work in a predominately white occupation. For example, visible minority police officers experience prejudice from Caucasian officers, harassment and barriers to professional mobility (Jain, Singh \& Agocs, 2000).

Moreover, Gould (2000) notes that a low representation of visible minorities in police organizations helps to perpetuate Caucasian officer's prejudices against visible minorities; this creates a climate of harassment for the few ethnic police officers and hinders their professional mobility.

The lack of racial diversity within the police force is a primary obstacle with respect to the career mobility of Black police officers. A qualitative study by Jain, Singh and Agocs (2000) concluded that visible minority police officers experience barriers to promotions and career advancement. Jaccoud and Felices (1999) found that visible minorities continue to be underrepresented in police institutions. Jayewardene and Talbot (1990) found that visible minorities make up $20 \%$ of the population in Toronto, but only $5 \%$ of the police force. In 1974, the Ontario task force on policing recommended more visible minorities be hired in the police force. Unfortunately, 25 years later in 1999, not much had changed.

An examination of current police force demographics suggests that despite the need for greater diversity, white police officers continue to occupy high ranking positions compared to their Black counterparts (Jaccoud \& Agocs, 2000). The problem of underrepresentation can be linked to the fact that the recruitment process and hiring decisions are largely controlled by white police officers. Additionally, police recruiting demographics indicate that white males are overrepresented in the police force, especially with respect to occupying positions of power (Jaccoud \& Agocs, 2000). A major problem in the career advancement of Black police officers is that the criteria for promotion is largely based on seniority, which creates a major obstacle for 
the promotion and career mobility for Black police officers that have only recently joined the force. Given that there has only been an emphasis on diversity hiring in recent decades, the lack of a long-term presence of Black officers in the police force may serve as a hindrance with respect to promotion decisions based on seniority (Jain, Singh \& Agocs, 2000).

\section{Conclusion}

This literature review has demonstrated the increasing need to explore the nuanced perspectives and experiences of Black police officers. Given that this group belongs to both a profession which exhibits inherent racial bias, in the form of over surveillance and the use of excessive (and even lethal) force against minorities, as well as belonging to the very minority community targeted by the police, it is imperative that we explore and understand the unique tensions Black officers face.

This literature review has put forth evidence suggesting that Black and minority communities experience over-surveillance by the police as a form of social control (OwusuBempah, 2014). Residents of predominantly Black communities are at greater risk for being stopped, searched and frisked during routine traffic stops (Carmichael \& Kent, 2014). The constant monitoring and oversurveillance of Blacks, and the inherent suspicion and racial bias of police officers, underpins the aggressive and excessive force tactics used by the police against these communities. The hostile tension not only induces and encourages distrust and fear amongst minorities, but it also leads to brutal acts of police violence (Smith \& Holmes, 2014). Police shootings are becoming increasingly common, and the media continues to deliver unfortunate news on yet another fatality of an unarmed black man (Carmichael \& Kent, 2014).

While police shootings may be considered a modern social phenomenon, the racial bias and discrimination traces back to historical roots embedded in slavery (Owusu-Bempah, 2014). 
This literature review has relied on critical race theory literature to demonstrate the history of social oppression and enslavement of Blacks. 


\section{CHAPTER 3. THEORETICAL AND CONCEPTUAL FRAMEOWORK}

The theoretical framework underpinning my MRP is a critical race theory. It began in the 1980's within law schools of the United States of America where activists and scholars came together with a shared concern about race, racism and power (Delgado \& Stefancic, 2000). Derick Bell is considered the intellectual father of critical race theory (Delgado and Stefancic, 2001). Bell examined the relationship between race, racism and power and how these relationships shape people's lives. Critical race theory identifies the discrimination that exists in society. For example, this discrimination is manifested as restricted access to housing, healthcare, employment, education, racial profiling by police, and the increased chance of criminalization (African Canadian Legal Clinic, 2012). Critical race theory argues that social institutions are designed to purposely give power to the dominant culture, white hegemony, while simultaneously creating racial barriers for visible minorities. Critical race theory critically examines the social construction of differences and how these differences operate in our institutions and produce inequalities that affect targeted groups of people (African Canadian Legal Clinic, 2012).

Critical race theorists understand the difficulty with combating racism as they recognize that society allocates privilege and status based on race, and in turn, racial hierarchy determines who obtains tangible benefits, including socio-economic status and power (Delgado \& Stefancic, 2001). For example, critical race theorists would argue that by simply belonging to the dominant race, white people are more likely to be afforded better job opportunities, and access to healthcare, and housing compared to Blacks (Awlward, 1999). Critical race theory discusses the

deep rooted anti-Black racism that exists today and relates it to the anti-Black racism of the past. Additionally, Awlward (1999) asserts, "historical-race focuses on how the racial group's history 
affects current issues" (p. 32). In this regard, Awlward is suggesting that by examining the past we can see how Black people continue to be affected today. Although slavery no longer exists in Canada, critical race theory identifies how Black people continue to be affected and treated unfavourably compared to whites.

Kimberlé Crenshaw (1991) and Patricia Williams (1991) brought an intersectionality approach to critical race theory. They brought attention to women of colour within overlapping systems of subordination. Crenshaw (1991) explained "I used the concept of intersectionality to denote the various ways in which race and gender interact to shape the multiple dimensions of Black women" (p. 1224). Williams (1991) discussed how race and gender should never be viewed separately because they are intertwined and shape Black women's lives. Through critical race theory, Crenshaw (1991) discussed the double burden that women experience from patriarchy and sexism and brought attention to the oppressive social conditions in which women and men of colour find themselves in. Although this paper does not discuss the experiences of Black female officers, it is important to acknowledge that the intersectionality of race, class and gender are an integral part of critical race theory and were introduced by Kimberlé Crenshaw and Patricia Williams. They were prominent figures in pursuing a path toward racial justice that is, ultimately, transformative (Williams, 1991).

\section{Interest Convergence}

Within critical race theory is the concept of interest convergence. Interest convergence is the idea that racism privileges white elites and middle class whites, and because of their privilege, they have little incentive for eradicating racism and speaking out against it (Awlward, 1999). Racism advances their opportunities so instead of speaking out against it, they prefer to remain silent. Another aspect of racial convergence is the idea that white people will support 
racial justice when it benefits them, but if it does not, they will not support it. Discussing the work of Bell (1994), Delgado (2000) explains that "gains for Blacks coincide with white selfinterest and materialize at times when elite groups need a breakthrough for African Americans, usually for the sake of world appearances or the imperatives of international competition" (p. 363). With respect to the concept of police violence against Blacks, and the experiences of Black officers, interest convergence can be seen to operate when officers (white or Black) do not speak up against the targeting of Black communities. In this way, interest convergence can be viewed as intersectional, and layered, extending beyond just viewing race as privilege, but also occupational status as well. Much like the Black officer that did not speak up for me when I was being targeted, interest convergence could have been operating when this officer did not want to jeopardize his job to stand up to the police harassment I experienced, and/or he chose to preserve his relationship with his colleague.

\section{Colour Blind Racism}

The emergence of critical race theory brought attention to the term colour blind racism. Colour blind racism is the claim that racism is no longer a structural phenomenon since race and racism no longer matter, and that social institutions treat everyone equally regardless of their race (Doane \& Bonilla-Silva, 2003). However, as Bonilla-Silva states: “colorblindness still has the same end goal as overt forms of racism; maintenance of white privilege. Whites receive material gains by adhering to racial ideologies that keep them on top" (Bonilla-Silva, 2003, p. 46). What is even more troubling is the way that Blacks are perceived through this colour blind lens. Rather than acknowledging the institutional racism that negatively impacts Blacks, some whites negatively stereotype Blacks by assuming that most them do not want to strive for 
anything to make themselves better, and that Blacks are culturally deficient compared to whites (Bonilla-Silva, 2001).

\section{Differential Racialization}

Critical race theorists Clair and Denis (2014) describe differential racialization as the process of distinguishing people based on their physical differences, such as the colour of their skin and other physical features, to create social and racial divides. In other words, perception and social constructs, not actual physical differences, are what separate people. Thus, the dominant group constructs these differences and gives meaning to racialized groups. These meanings give the dominant group power and privilege over all non-white groups. Campbell (2014) notes, "racial constructions enforced and accepted by the dominant racial group ultimately serve as a tool for placing racial and ethnic minorities in the category of "otherness" (p. 75). For those who do not have equal access, differential racialization is very real and pervasive. Being white means that you have advantages that people who are not white do not have. Although differential racialization affects racialized groups in different ways, critical race theorists purport that white people are advantaged because their physical attributes reflect the dominant social hegemony.

\section{Whiteness and Surveillance}

Guess (2010) defines whiteness as the norm and group of people who sustain social privilege while all other groups are marginalized “others.” Moreover, Ahmed (2007) notes, "whiteness becomes a social and bodily orientation given that some bodies will be more at home in a world that is orientated in whiteness. In relation to this research topic of police and racialized communities, Thobani (2007) discusses whiteness and how it is used as a form of surveillance on racialized bodies. Certain bodies are monitored as they move through space. Ahmed (2000) 
discusses the concept of the good citizen as being the one who suspects rather than is a suspect, who monitors the neighborhood to ensure the space is safe from anything or anyone that does not belong there. Thus, the unwelcomed Black body becomes synonymous with violence and whiteness looks at the Black body as inferior (Thobani, 2007). Bodies that are not white are stopped and questioned by police. For example, the police stopping Black bodies as they move through predominately 'white spaces' and white neighbourhoods (Thobani, 2007, p. 161).

\section{Critical Race Theory Continued}

Critical race theory promotes activism and seeks to identify racial hierarchies and facilitate social change (Delgado \& Stefancic, 2001). Critical race theorists propose that encouraging dialogue about race, racial structures and discrimination as early as elementary school is imperative in dispelling negative stereotypes (Delgado \& Stefancic, 2001). Encouraging dialogue and discussions involves using story telling as a powerful tool to give a voice to those who may have gone unheard or silenced by the homogenous white culture.

Critical race theory proposes that using stories from as far back as slavery to better understand the experiences of Black people during that time is an important way to facilitate social change (Delgado \& Stefancic, 2001). Storytelling can bring to light the reality of the experience of Blacks and help non-Blacks understand what it is like to be Black and provide a glimpse into a reality that they are not familiar with. The goal of storytelling is to educate the public so these stories can reach as many people as possible and impact change (Delgado \& Stefancic, 2001).

Stemming from storytelling is the concept of counterstorytelling, which are stories that are used to challenge, counter, and critique false stories that were created by dominant groups and ingrained in society for too long. Delgado and Stefancic (2001) explain, "Many victims of racial discrimination suffer in silence, or blame themselves for their predicament. Stories that 
counter the dominant ideology can give them voice and reveal that others have similar experiences. Stories can name a type of discrimination; once named, it can be combated” (p. 43).

The social goal of critical race theory is concerned with equity, and to ensure that minority groups are treated with fairness and are not discriminated against (Delgado \& Stefancic, 2001). Critical race theory is concerned with social justice and recognizes that the law has failed Black members of society. As scholar and activist, Dr. Martin Luther King once claimed: "law and order exist for establishing justice and when they fail in this purpose they become the dangerously structured dams that block the flow of social progress" (Awlward, 1999, p. 14). In this way, the problem of blocked social progress could be remedied by the concept of critical race theory. Allowing stories of Black marginalized communities into conversations about law and order could help the police force better understand and empathize with the racial groups they monitor and police.

Using critical race theory as the theoretical framework of my research topic is suitable because it uses an analytical lens to explore the institutional racism that is pervasive in the dominant culture. Critical race theory explores these power structures that give police officers the power to regulate behaviour and enforce order as they see fit (Lawrence, 1995).

Deconstructing power structures is imperative in critical race theory as it assists in dispelling the perception of the racialized body as a threat. Using the lens of the critical race theory, one can glean that Black bodies are not inherently dangerous; they are only perceived to be dangerous within the context of a systemically racist social order (Delgado \& Stefancic, 2001). To assist racialized individuals in sharing their experiences and mobilizing their stories, this research will use a critical race theory lens. The importance of sharing and talking about one's experiences as a racialized individual is an important part of critical race theory because it 
challenges myths, and constructs a different reality (Delgado \& Stefancic, 2001). For this research, this means capturing the essence of the experiences of four racialized police officers. 


\section{CHAPTER 4}

\section{Methodology}

\section{Research Design}

To understand the essence of the experiences of Black male police officers, I will be using qualitative research design for this study. Qualitative research can address real life issues giving people the opportunity to talk about their experiences in personal and social contexts (Gelling, 2015); this means Black male police officers talking about their personal experiences. Qualitative research has benefits that cannot be obtained by using quantitative research, such as emotions and ideas being examined in detail and in-depth interviews that give the researcher the freedom to adjust the flow and redirect conversations in real time (Gelling, 2015). Qualitative research allows the researcher to ask questions that are multidirectional and give the interviewee the space to elaborate on anything that they feel is important to discuss (Gelling, 2015).

\section{Research Approach}

The research approach that I will be using for this study is phenomenology.

Phenomenology is about describing the lived experiences of people (De Chesnay, 2014).

Phenomenology is about talking with multiple individuals who have experienced a phenomenon and seeks to understand the common meaning of their lived experiences. Edmund Husserl was one of the prominent figures in advancing phenomenology as a research method. He believed that research participants telling their own stories was an accepted method of research (Pickler, 2011). Moreover, a phenomenology approach focuses on the desire to understand humans from their own subjective experience and not from the perspective of others (Gelling, 2015). Phenomenology is considered descriptive as it describes the experiences of research participants (De Chesnay, 2014). Gelling (2015) asserts, "Personal experiences are most often collected 
through in-depth interviews, which can be analyzed to formulate meanings. These meanings are often presented in a coherent story of interrelated themes and insights, which can help explain the nature of the phenomenon being investigated" (p. 45). This approach was used to explore my research topic as I conducted interviews with four Black male police officers and used interrelated themes to describe the experiences of these research participants. Phenomenology was particularly useful in this research study because this approach can look at change processes over time, help to understand people's meanings of things, and help to adjust new ideas and issues as they emerge (Dudovskiy, 2016).

\section{Research Criteria}

The research criteria for selecting study participants used snowball sampling. Snowball sampling uses specific characteristics to determine who will be involved in the study. Snowball sampling consists of identifying respondents who are then used to refer researchers on to other respondents (Atkinson \& Flint, 2001). As noted by Atkinson and Flint (2001), "Snowball sampling can be applied for one primary purpose. It is an 'informal' method to reach a target population. If the aim of a study is primarily explorative, qualitative and descriptive, then snowball sampling offers practical advantages. Snowball sampling is used most frequently to conduct qualitative research, primarily through interviews" (p. 1).

\section{Research Participants}

The research participants for this study included male police officers who identify as Black and/or African, and/or Caribbean, and/or American and/or Canadian and worked for, or presently working for, a policing institution in Canada. There is no specific duration of time that an officer had to have worked for an institution. I interviewed this demographic because it is important to uncover the experiences of several Black male police officers, in a white male 
dominated profession. Research has shown that Black male police officers are treated differently in the police force, but it is important to talk to them to obtain an in-depth understanding about how they feel about being a police officer and the essence of their experiences. These participants are selected because they can best inform the research questions and the phenomenon under study.

\section{Recruitment}

This research used word of mouth recruitment. Word of mouth requires other people to participate in the recruitment process and share information about the study on behalf of the researcher (Susan, Jennifer \& Schweitzer, 2008). I asked people that I knew in my social networks, which includes friends, colleagues and people in my neighborhood to share my verbal recruitment script. I reached out to my social networks through email and I communicated with them orally in person. My verbal recruitment script included the information needed to give potential research participants a clear understanding of my research study (see Appendix A). My email address and phone number are included on the verbal recruitment script and any police officer that was interested in my study was able to contact me if they had any questions about the study or were interested in being in the study. For this study, I was not interested in generating findings which are generalizable to a general population of police officers. In fact, due to my method of recruitment, which is word of mouth, and not random sampling, my findings are not generalizable.

\section{Data Collection}

I conducted in person interviews with four participants. Using semi-structured interviews, interviews lasted between 1 to 2 hours. Semi-structured interviews allow the researcher to come up with an interview guide with questions, but this guide is used to facilitate the conversation (see appendix B). It is not used to schedule explicitly specific questions, but rather it can be used 
to incorporate these questions throughout the interview (Newton, 2010). Pietkiewicz and Smith (2012) explain, "Semi-structured interviews allow the researcher and the participant to engage in a dialogue in real time. This also gives enough space and flexibility for original and unexpected issues to arise, which the researcher may investigate in more detail with further questions" (p. 5).

\section{Data Analysis}

I started by listening to the interviews multiple times to help immerse myself into the data. This helps the researcher recall the setting where the interview took place (Pietkiewicz \& Smith, 2012). During this stage researchers can make notes about observations and reflections during the interview experience, the language used, and interpretive comments (Pietkiewicz \& Smith, 2012). Chase (2003) defines interpretive comments as stopping and writing about what is going on in a specific passage or moment during the interview, where the researcher focuses on what is important about that passage, what the person is trying to communicate, and what the researcher finds particularly interesting about that passage.

I used open coding, which is a process of reducing the data to a small set of themes that appear to describe the phenomenon that is under investigation (Pietkiewicz \& Smith, 2012). I used a colour-coding or numbering system to identify text about the different themes, grouping together ideas and gathering evidence about views on each theme. For this research study, there was a maximum of 25-30 codes plus or minus five. During coding, I also engaged in memoing, which is reflecting on the data and writing memos to myself. Bailey (2008) explains that "during this memoing stage the researcher creates, defines and refines conceptual categories, and makes tentative notes about links between concepts" (p. 133).

During data analysis, I came up with themes that emerged from the data and put them into categories. I took these themes and examined them across the multiple interviews. 
Pietkiewicz and Smith (2012) assert that "the next stage involves looking for connections between emerging themes, grouping them together according to conceptual similarities and providing each cluster with a descriptive label. In practice, it means compiling themes for the whole transcript before looking for connections and clusters" (p. 8). Chase (2003) describes using emerging themes to articulate similarities between interviews, using direct quotes to demonstrate these similarities, but also describing the meaning of these themes in your own words.

\section{Confidentiality}

Research ethics board approval was received from Ryerson University for this research. All personal information of research participants was kept confidential and only the researcher had access to this information. Any information pertaining to the research participants was stored in a password protected file. None of the research participants' personal information was used and instead of using their real names, pseudonyms were used. Once I completed the first draft of the research, all their personal information was destroyed. Participants were reminded about confidentiality before and after the interview and reminded that if they have any questions or concerns, then they could contact me at any time (see appendix C). No personal information pertaining to identity was included in the completed research publication. Participants were asked to review their interview guide (see appendix B), as well as approve the final research paper to ensure that they were comfortable that the information did not identify them to potential readers.

Participants were informed that interviews could take place at Ryerson University and that a private room would be secured with aural and visual privacy to ensure confidentiality. This is especially important due to the sensitivity of the information that may have come up in the 
interview. Participants were informed that they could choose a location where they would like to meet as long as it is a secured place with aural and visual privacy to ensure confidentiality. Public areas like coffee shops were not used for interviews due to the sensitive nature of the research topic. 


\section{CHAPTER 5. FINDINGS AND ANALYSIS}

As part of a comprehensive review and analysis, my MRP includes a findings and analysis section to describe the responses of participants in the study about their experiences as Black police officers. The aim of providing direct quotations from participants is to offer context and analysis of the daily lived realities for the members of the very group my MRP focuses on, Black men working in the police force. I interviewed a total of four participants. All participants were Black males, with experience working in policing from five to over twenty years. The participants have a range of work experience, working for multiple policing agencies including various municipalities in Canada as well as the RCMP. An important part of interview research is to create an environment that is conducive to gathering robust and accurate information and details from participants. The purpose of curating various locations to conduct my interviews was to elicit a variety of responses, and to create a comfortable and casual atmosphere where my interview participants would feel open to share candidly their experiences with me. Prior to the start of each interview, I asked each participant if they were comfortable with me recording the interview and transcribing their responses to integrate within my research. Once I obtained the appropriate consent, I recorded the conversation, and shortly after pressing 'record' my interviews became very relaxed and comfortable.

With specific reference to the structure and style of the interview, each participant took part in a semi-structured interview which allowed them to answer a pre-determined set of questions, and elaborate and explore themes further. The four participants either currently work as police officers or previously worked as police officers.

\section{Theme 1 -THE GLASS CEILING: PROFESSIONAL OBSTACLES}


To discuss this issue of structural and systemic racism within the policing institution, I asked my interview participants about their thoughts and ideas about racism, in the form of AntiBlack racism in the police force. The responses I received varied, from intense agreement and passion about the negative experiences of Black officers in the force, to abstained trepidation, and a hesitancy to use the words "racism." Some of the participants expressed hesitation to openly discuss their personal experiences of discrimination, and limited the amount of information they wanted to share with me, perhaps due to the possibility of being identified. To protect the privacy of the individual participants, I have identified their responses using only numbered participants (i.e participant 1). I have organized the responses of my interview participants by categorizing responses according to consistent themes and patterns that emerged from their responses.

\section{Glass Ceiling for Black Officers}

A major theme that arose from the interviews was the concept that despite being qualified and having the necessary experience and knowledge as police officers, Black officers were nonetheless consistently turned down for promotions and experienced obstacles in career advancement. In this regard, I found that Black officers in the police force experience a 'glassceiling' when it comes to advancing in their careers. Perhaps the most salient, and interesting fact is that while all the participants recognized the lack of career mobility, there was a sense of acquiescence in the frustration. While all the participants felt that it was unfair to be treated negatively and have their careers stalled, almost all recognized that that is 'just the way it is' because of the historic and social structure of the policing institution. Above all, there seemed to be a sense of resiliency, in these officers despite the frustrations and recognition of a racist police force. The Black police officers that I interviewed knew that the status quo is unjust, but they had 
developed strategies and methods to cope, adapt and persevere despite the obstacles and challenges they faced in their careers.

With specific reference to the lack of career mobility, restricted career advancement and the existence of a 'glass-ceiling' in the police force, one participant mentioned:

"I have over 30 years of policing experience and I was always walking in the wind... They perceive you as a threat if you are a Black officer and you try to become more in relation to your policing activities than they want you to be... The first Black officer was hired in 1967, the first Black promotion to the lowest rank was in 1995. That's 28 years later, 28 years before there was one promotion. I have a term called racial tailoring, minimizing your accomplishments and restricting your opportunities and racial showcasing, where you put a black person up there to be the first, the only and in the highest position so that the public will feel that there is progress being made, when in fact racial tailoring is going on behind the scenes."

Participant 1, April 2017

An interesting discussion arose about the term "racial tailoring" where this participant discussed the idea that within the police force, the accomplishments and achievements of Black officers are generally minimized and downplayed. However, the police force may make it appear to the general public that Black officers occupy positions of power and influence within the police force. This participant had good reason to feel that the public perception is much different than his reality. This research participant worked as a police officer for over 20 years and has not received a significant promotion in all his time with the police force. In a similar vein, another participant described the exact same concept of feeling restricted in his career as a Black police officer. This participant expresses his frustration with feeling stuck and 'pigeon holed' in his career. Despite his desire to advance in his career, on his own terms, this participant communicated his issue with the fact that his career is 'pre-determined' as he is relegated to police Black communities. This participant further explains that in addition to being assigned to police neighbourhoods with higher rates of poverty and crime, there is also a lack of support and resources for him within the policing institution. This participant expressed a desire to expand 
his career and move up in the ranks, experience diverse and different aspects of his career,

however, he felt no support from his superiors to help him do so. Participant 3 explains:

"The policing institution as an organization has predetermined or pigeon-holed the Black police officer contrary to the direction you have for yourself. So, when you're hired as a Black police officer, they have already predetermined what they want to utilize you for and predominantly as a Black police officer you are put into specific positions. They see exactly where your career should go to, and that is to work in Black communities or marginalized communities. There is no initiative to help you promote up the ranks or to be more diverse in different aspects of policing. It is this belief that white people are superior that limits our ability as Black police officers to move up."

Participant 3, May 2017

Participant 4 described a very similar fate of feeling like his career as a Black police officer was limited and restricted as he was passed up for a promotion by a white supervisor. This participant felt that being told that he 'was not ready' for a promotion, without being offered a substantive reason as to why he was not ready was directly attributable to his race. Moreover, this participant expressed frustration with being denied a promotion, despite more than five years of dedicated service. In addition to being blatantly rejected without a good reason as to why, this officer was not offered a career direction or plan to help him become 'ready.' Rather than offering a viable solution and plan to help this officer advance in his career as a police officer, his request for a promotion was met with flat our rejection and lack of support. Participant 4 explains:

"I have applied for a job in the past and there was a white supervisor and her standpoint was, and she said to me, just because I think I am ready for a promotion does not mean that others are ready for me. What she meant by that I did not know for sure, but I felt like she was suggesting that me being an African Canadian meant the policing institution was not ready for me to get a promotion because I look different than the white police officers."

Participant 4, May 2017| 
Additionally, another participant also explains that they were not even considered for a job and the white hiring officer did not even take the time to read the Black officer's resume before blatantly rejecting him for a position. Participant 3 states:

"I had a job interview and was told my skills don't match my qualifications. I told them my resume does match the qualifications by giving examples. The supervisor said he didn't know that it said that in my resume and would consider it. He didn't even take the time to look at my resume before telling me I was not qualified for the job. That job was already predetermined for a white police officer regardless of my qualifications."

Participant 3, May 2017

Many of these officers tried to make sense of, and rationalize the unfair obstacles they experience in their careers in the police force by turning to the historical oppression experienced by Black people in a structurally and predominately white organization. It is important to highlight that despite these obstacles of unfair treatment, the participants maintained resilient and positive attitudes throughout my discussions with them. As participant 2 explains:

"Culturally speaking, police organizations are run by white males. In any aspect of employment or labour, the dominating culture will never allow another culture to take over their culture in relation to economics, education, labour, law, politics, religion, sex and war, and the policing institution is no exception."

Participant 2, May 2017

In this regard, the police officer recognizes that what is against him is years of structural racism, inherent in the very fabric of the institution. This participant is neither lamenting his situation, nor is he expressing anger, he is merely pointing out that the obstacle he faces is one that is engrained so deeply in the institution that expecting any change may be a fruitless endeavor.

In another account, a participant explains the lack of consistent training and inconsistent career development he received, compared to his white counterparts. Like the objective attitude displayed by the police officer above, this participant is merely observing the racialized 
undertone of his inconsistent training, and pointing this issue out as a matter of fact. As one participant observes:

"I started working at a policing unit and other white officers were hired with me at the same time. We were each assigned a training officer that we would work with for three months. What was interesting was after a week working with the trainer assigned to me, I was told I would be assigned to another officer. What ended up happening is that I worked with over 15 different officers in that three month period. I was passed on from one officer to the next. Therefore, my development was negatively impacted because there was no consistency in my learning. What is even more problematic is that the white officers that were hired with me had one to two training officers in that three month period. When I break down all the factors to understand why this was the case, the only thing that I am left with is that I look different than the other officers and that was the reason why I was treated differently."

Participant 3, May 2017

The response of one of the research participants represents a level-headedness and stoicism, one where he noticed the racism and yet chooses not to take his complaints further, in a formalized process. Given the ongoing lack of support experienced by these police officers, this may contribute to their understanding of not taking the time to vocalize their concerns. None of the police officers I interviewed expressed anger, nor did they spend much time complaining, or acting as a 'victim' of their circumstances. However, as I will discuss in the 'Implications' section of this MRP, while the positive attitude of these police officers is commendable because they are strong and resilient, there also exists a major issue as these officers may feel precluded from making a formal complaint about the racist behaviour and discrimination experienced in their careers. It is possible that in instances where a police officer decides not to bring forward a formal complaint, the underlying basis of this decision may be his understanding of the structural racism within the police force. The next theme will discuss the issue of belonging and the social identity of police officers. 


\section{Theme 2 - ISSUES OF IDENTITY AND BELONGING}

As discussed in the introduction section of this paper, a major issue experienced by Black police officers is the racial tension between officers and the Black communities they police. Because of this unique social experience, the social experiences of Black male officers are exacerbated; not only do these individuals belong to the police force, but they belong to a visible minority group. Du Bois (1903) discusses the term double consciousness and the experiences of the Black man always looking at himself through the eyes of others. Essentially, he is saying that Black police officers have this ambivalence as they know how to survive in two worlds through double consciousness. They understand how the white world views them and this allows them to navigate their lives accordingly. Du Bois (1903) would argue that this double consciousness provides Black police officers with the understanding to navigate their lives between both groups. It is also equally possible that the dual-identity of being Black and a police officer affords these individuals with strength of insight, perspective and the ability to adapt to a variety of environments. In this regard, professional and racial diversity should be viewed as a strength to be celebrated, not a hindrance to be avoided.

The following will outline the internal conflict and unique issues faced by Black male officers, regarding the social identities as Black males and professional identities as members of a homogenous and predominately white police profession. Within the theme of identity and belonging, two salient issues arise from the interview responses. As my research indicates through the interview responses, the first most salient point raised by the participants is the intense need and pressure to fit in with their police colleagues, and yet never fully achieving conformity. They are neither fully trusted by their officer colleagues, nor are they trusted by the Black communities who sometimes view them as traitors and 'sell outs.' 
In discussing the need to fit in within a predominately white profession, one participant describes the questions he asks himself when trying to assimilate to each situation. His explanation evokes a sense of tension with respect to who to 'impress' while trying to conform to cultural expectations of the profession.

"You have to remember that because you are a minority within a majority you know there is increased pressure to fit in. If you end up in an organization where 0.0 percent of people look like you, then there's a tremendous amount of pressure for some folks to try and fit in. And obviously, the younger serviced you are the more pressure there is. Some folks will react in a funny way so you never know how they will react. Will they react and try to impress? Some folks will do that; there is absolutely no doubt in my mind that some folks would do that. Matter of fact, I have experienced in my service some Black officers would make Black jokes to try and fit in. There's no telling what some people do to try and fit in."

Participant 1, April 2017

This officer is describing the tension he feels when he assesses the lengths some Black officers will go to when trying to adapt to their new police officer identity. He aptly points out that younger officers are more prone to pressure to 'reject their Blackness' by making fun of themselves and making Black jokes. By using Black jokes, these police officers are using humour to distance themselves from being Black, to disarm their (white) police officer colleagues of their skepticism and to reject their own identities as Black individuals. Nonetheless, the underlying use of such humour is that self-deprecation may be used as a tool to empower oneself in the face of racism. To make fun of oneself is to essentially take away the opportunity from others to make-fun of you. This may be a strategy used by some Black police officers. Above all, the most obvious issue is the fact that the pressure is felt, both internally and externally, to fit in.

Another participant identifies the same pressure he faces of trying to fit in. This participant describes the uncomfortable pressure to conform to the expectations of his workplace in the context of it being a challenge and a struggle. He grapples with the issue of knowing that it 
is important to fit in as a police officer, but also the difficulty that comes with achieving this conformity in a real and authentic way. This participant admits that despite years of trying to be part of the culture and team as a police officer, he feels he will never truly be accepted. In addition to existential questions of belonging and dealing with his own identity issues, this officer notes that he will never know if his colleagues are his true allies, as he has a hard time distinguishing who views him in a negative light due to his skin colour. Participant 2 states:

"Struggling to know where I belong is a fair question to ask. In any workplace, you want to fit in because you want to be comfortable going to work. The struggle then becomes what if work itself makes you uncomfortable. Should you have to adjust to fit in at work or should your workplace make everyone feel comfortable. That is the problem I have had for many years. I never feel truly accepted or treated as an equal at work. Don't get me wrong, there are good people in the policing institution, but the system itself does not make Black officers feel included. On top of that, add the way that the Black community perceives you because you are an officer and it makes it that much more complex. Again, not all black people in the community see you in that light. But because there are many who do see you in a negative sense and there are many cops who see you in a negative sense it becomes harder to distinguish who does and who doesn't. Being a Black police officer is not easy because you are constantly challenging your inner thoughts and trying to know your place in society."

Participant 2, May 2017

In another account, participant 3 expresses a similar trepidation and concern when it comes to feeling accepted by his colleagues. This Black officer specifically cites a lack of having personal relationships with his white colleagues, despite serving as a police officer for over 24 years. He explains the lack of closeness between himself and his white colleagues in the following:

"I have been working in the police department for over 24 years. Now I can count on one hand how many officers that are not Black that I have a personal relationship with or had invited me into their home or I have invited them into mine. Now that is very disturbing when you look at the amount of time you spend at work with your peers. You have individuals that have no inclination to work with Black people and can't uncheck their bias in them and you can't retrain these people because these thoughts are heavily ingrained in them." 
Participant 3, May 2017

This participant notes that despite working closely with his white colleagues at work, he has never been invited to one of his colleague's home for dinner, nor has he engaged in social activities with his co-workers that are non-Black. Participant 3 aptly notes that this is 'disturbing' given his long service. The fact that this police officer notes this as an issue which he finds disappointing indicates that he would want to have social interactions with his white police officer colleagues, but feels that his Blackness precludes him from having close personal relationships outside of work. Interestingly, the lack of closeness with colleagues is only reserved to non-Black co-workers, meaning he is able to have close personal relationships with his Black co-workers. The problem with Black officers feeling that they can only connect with other Black officers is that an enclave is created which isolates Black officers and prevents them from being fully integrated within the policing institution.

In contrast to participant 3 , who has expressed his disappointment from not having white police officer friends, participant 4 reacts very differently to the same issue. In describing the fact that he has no close friendships with white colleagues at work, participant 4 frames this as his decision citing that he did "not come to work to make friends." This police officer does not point out structural racism as the main issue underlying the lack of connection. Instead, this participant explains the lack of inter-racial friendships at work as a deliberate choice. Participant 4 states:

"The way I view things is that I am not there to assimilate and I've had to speak to white officers and tell them straight up that I did not come into this job to make friends. I have friends before who became police officers, but I have very few friends who were police officers and became my friends after. Even up till now after 25 plus years of policing, I still feel like an outsider. I still go to work and not feel 100\% comfortable. It could very well be because I am picking up on negative feelings from the white officers I have worked with. 
This officer starts by saying he does not intend to make friends with white police officers, but in the same sentence notes that he feels uncomfortable at work, even after 25 years of working as a police officer. He goes on to note that a reason for his feeling uncomfortable could be attributed to the 'negative feelings he receives from white officers' but he does not elaborate on this further. It is possible that two divergent inferences may be made here. First, it may appear that this officer prefers an environment where he does feel comfortable and safe, and perhaps have positive relationships, yet he rationalizes the lack of social connection with white colleagues as his choice and decision. The second possibility is that by refusing to be friends with those he considers racist, this officer is empowering himself to fight against racism. It may have been beneficial for me to probe this question further, but I did not want to offend my interviewee as I felt this was a sensitive topic.

In addition to feeling out of place among their white police officer counterparts, the Black officers I interviewed also pointed out the uncomfortable experience of policing Black communities that viewed them as "traitors" or "sell outs". In all the police officer accounts that identified this conflict, all the participants mentioned being called the derogatory term of "Uncle Tom," by Black individuals while on the job. For background, the term "Uncle Tom" is a derogatory term referring to an excessively subservient person, particularly when that person is aware of their own lower-class status based on race (Richardson, 2007).

One participant describes an experience when he first started his job as a police officer where he interacted with a Black member of the community during a routine traffic stop. This Black officer mentions the shock he felt from being called an "Uncle Tom" when he was merely following his supervisor's orders. 
"I had a situation where I was being trained by a white officer and the Black person that I ended up pulling over in traffic stop called me an Uncle Tom. He didn't know that I was being trained at the time and I did not have a choice as I was following direction. I led the interaction and my colleague stood on the side to observe me on the job. Obviously, it was an ignorant standpoint from his side to call me and Uncle Tom and then he praised the white officer I was with on how great of an officer he was. The white officer did not engage him at all, but this speaks to the way that I can be perceived by my own community."

Participant 2, May 2017

Another participant expresses a similar frustration from not being accepted by the Black community when he is merely "doing his job." In addition to being told he is an "Uncle Tom" by a father, the father did it while his ten year old son was watching. This imposed upon the child, the father's views about the Black police officer. This participant talks about how trying to appease the Black community while carrying out the duties of his job is a 'balancing act,' which can be frustrating as he feels backlash from his own community. Participant 3 explains:

"The Black community wants representation and oftentimes prefer the presence of Black police officers, but then they are upset when you must do your job, so it's a frustrating balancing act. Because I worked in the Black community, your first introduction as having been from the Black community and work there initially is we want you to be Black and are thankful to have Black police officers here that are from and represent the community, but then you get complete backlash on the reverse end when you are dealing with someone's son."

The problem of dealing with the pressure of conforming to their police officer identity and the backlash from Black communities for "selling out" as an "Uncle Tom," is that Black police officers note that they experience intense pressure to be tougher on Black communities. It follows that by over performing their duties as a police officer, being more serious and tough on Black individuals would make it appear that they are more committed to their profession, to the exclusion of their Black identity. The result of being tougher on Black individuals is that it reproduces racism and targeting of Black communities, and also creates internal conflict or 
ambivalence for the police officers who feel compelled to choose between one or the other identity. Participant 1 demonstrates this internal tension as he explains:

"White officers praise a black officer for being tougher on his own community. Sometimes you're in a police state or you're in a police institution and you want to assimilate to fit in and what ends up happening is that you end up losing or giving you your own culture. Your culture is lost and therefore what culture do they carry. They end up adopting the police culture. Unfortunately, those are the officers who are readily accepted by the white officers."

Participant 1, April 2017

The unfortunate, yet common, situation described by this participant is the conflict faced by Black officers that feel compelled to be tougher on their own communities. They feel forced to 'choose' their profession over their racial identity, and give up their ethnic culture in favour of their occupational identity. Performing their duties as a police officer necessarily entails targeting Black individuals, being called an "Uncle Tom" and putting the interests of the homogenous policing institutions over and above the interests of the marginalized communities in which these officers are forced to police. The conflict and negative experiences, and social stereotypes experienced by Black police officers and their communities are explained in the following theme.

\section{Theme 3 - NEGATIVE STEREOTYPING}

As evidenced by increasing negative media attention, and numerous academic articles, Black communities are represented in a negative light using social stereotypes. Negative stereotypes mean that members of African-American communities are disproportionately targeted by police based on their race. As reported by criminologist Scot Wortley (2011), because of social stereotypes and negative representations, Black males not only experience over surveillance, but they are also more likely to be targeted, both through physical force and detention, by the police. Moreover, negative social stereotypes of Black communities create an 
oversaturated police presence, which generates more fear and tension between officers and members of racialized communities. When asked if police officers perpetuate or reify negative social stereotypes about Black communities, all my interview participants answered that question affirmatively. The Black police officers noted their observations about the associations of Blackness and inherent criminality. Many of the participants mentioned the fact that not only do police officers make important decisions about how to carry out their policing duties based on negative stereotypes, but most often, there is no effort made by the police to attempt to dispel negative stereotypes or even get to understand and learn about the Black communities they police. I asked participants "Do the police have negative views on Black communities, based on stereotyping? " In response to this question, participant 1 draws upon his 20 plus years of police experience and candidly explains:

"Absolutely, Absolutely! There's no ifs and or buts about it and I can only speak for me personally and I can only speak on behalf of my experiences, but I would say that most of the police officers that I've encountered in my 20 plus years of experience that I've been on the police force have been from small rural locations and their biases immediately come into play because they've never had any interaction with Black people. So if they've never had any positive interaction or any interaction at all, then the first interaction they will have from a police perspective is going to be negative. Their perception of Black people will continue to be negative as they continue to have negative interactions."

Participant 1, April 2017

This officer notes the inherent problem is that the lack of positive views on Black communities naturally reinforces negative stereotypes. Given that the police are called most often in moments of conflict, problems and alleged crime, and not in situations of peace and calm, the interactions that police have with Black communities is often negative. Moreover, the fact that these officers are white, and often do not have much experience dealing with Black communities outside of work, especially if they come from rural locations, the stereotype just continues to recreate itself. Participant 4 responded to this question with a very similar 
conclusion, pointing to the fact that white officers often do not have interactions with people outside of their race, since they may be from remote or small communities that are predominately white. The views of racialized communities held by white police officers are therefore limited to what they see on television, or in the news media. Participant 4 observes:

"The problem is that a lot of the police come from rural parts of Canada and so the images that they see on TV of Black people are heavily ingrained in their thinking. For example, one officer that I worked with and he has since left my area of policing and gone back to a totally different community all together came from up North and he had never seen a person other than a white person. So, what experiences or what skewed misconceptions is he bringing to the table. I would talk with him he would say certain things and hold certain views that were problematic and worrisome."

Participant 4, May, 2017

The account of this officer raises an important question about whether white police officers have appropriate cultural and sensitivity training. The lack of exposure to racialized communities is an inherent problem for a police officer that is supposed to be able to police multi-cultural and metropolitan cities. It is important to note that cultural and sensitivity training has its limits. It is possible that such education training may still be inherently biased and run the risk of reproducing negative social stereotypes about racialized communities. It must also be pointed out that if the policing institution is structurally racist, it follows that training efforts on sensitivity will be limited by the constraints of deep rooted racism embedded in the system.

Beyond the fact that there is clearly a lack of experience with how to handle delicate cultural and racial differences, it appears that the white police officers described by my interview participants did not make much of an effort to educate and inform themselves to better understand Black communities and the issues that members of these communities face. As mentioned by participant 3:

"I would have to say yes, police officers do stereotype the Black community. I think that they do not take the time to study the cultures of the Black community. If they see a Black 
man standing on the corner, for example, they would think that maybe there is some criminal activity going on, when in fact, Black men have always stood on the corner. That was the old time internet, where we would meet people to find out what's going on in the community. It didn't necessarily constitute criminal activity."

Participant 3, May 2017

Participant 2 similarly identifies the lack of education and lack of interest in better understanding the Black community as a major contributing factor to the reinforcement of negative stereotypes. Participant 2 observes that:

"On mass, officers no longer spend time getting to know the community. Before I would sit in a restaurant, and chat with people in the community. To the community they would see this as socializing with community members because I would do that wherever I went in the community. Today, this does not happen anymore. We go into the community to police the community, but where is the communication aspect of that? How are officers going to remove the stereotypes they have of communities who do not look like they do if they are not willing to get to know the community?"

Participant 2, May 2017

In describing the situation, participant 1 suggests that to remove negative stereotypes, it is necessary for police officers to get involved in the community and encourage dialogue and communication between officers and Black community members. In expressing the importance of communication, participant 3 highlights the fact that learning more about a culture helps reduce negative stigma. Therefore, in the context of policing, officers must learn about the diverse populations in order to effectively do their job. Participant 3 explains:

"The more I know about a culture the less skewed my lens will be about that culture. The more familiar we get to a subject or a people, the more open we will be toward others. Oftentimes people say negative stereotyping is a police issue, but an individual officer is a person. Police officers as individuals need to spend time learning more about the communities they work in and the diverse populations they serve to combat the negative stereotypes that exist and influence their thinking."

Participant 3, May 2017

The response of this participant is connected to critical race theory's notion that encouraging dialogue about race, racial structures and discrimination is imperative in dispelling 
negative stereotypes (Delgado \& Stefancic, 2001). Within the context of policing Black communities, encouraging dialogue and discussions is important for Black communities to be heard and to have a voice against the social stereotypes they face. The problem with social stereotyping is not only that it increases fear and tension, and encourages police officers to respond with more force and violence than necessary, but also the fact that stereotypes impact the lives of Black officers who are subject to negative views from their colleagues. The implications of stigmatizing Black communities as criminal are that Black police officers also experience discrimination, whether in uniform or not.

As described by participant 2 , the social stereotyping was so intense that he almost quit his job several times. Despite now having over 20 years of experience as a police officer, participant 2 says of his earlier police days:

"Throughout my years as a police officer, especially in my earlier years, I can remember countless times that I would come home to my family telling them I want to quit because of the way that I was being treated and the way that these police officers were treating my community. The negative stereotyping that they had toward my community was being felt by me in the way that I was being treated in the policing institution."

Participant 2, May 2017

Another police officer notes that despite being a law abiding citizen and police officer, he will never be able to escape the colour of his skin. To society, he will always be viewed as a young black man that must be viewed closely and held under constant surveillance. Participant 3 explains:

"As a young Black officer, you may take off your uniform go about your business as usual and still be considered or seen as a young Black person that needs to be surveilled and some police officers still may negatively stereotype you because you're a young Black man and they don't know what your situation is. I see what is happening around the world and in my communities and I never forget the colour of my skin whether the uniform is on or off." 
Both of these responses elicit the notion that despite their best efforts, these police officers will likely be subject to the negative stereotypes that impact not only the Black community in general, but themselves as individuals when the uniform comes off. As the next section will demonstrate, in order to dispel stereotypes going forward, a major issue is to encourage change through education and learning more about others and others' cultures in order to help police officers understand Black communities, and help Black police officers to be included both within their profession and ethnic communities.

\section{Theme 4 - Police Officer's Recommendations}

A major part of my research efforts is to ensure that not only are the problems and issues found by Black male police officers identified, but that future recommendations and solutions are proposed to address these issues. For that reason, I dedicated a portion of my interview time with my participants on inquiring into their ideas about what needs to be changed within the policing institution. By directly asking these Black male officer participants what they believe needs to be changed, I am able to offer a unique perspective that comes from within the very institution I am researching. In response to the question, "What needs to be changed, and what should the next best steps be going forward?" the participants raised two main propositions.

First, all the participants noted a need for more diversity within the policing institution. They pointed to the fact that despite increasing numbers of racialized people being hired into the police force, the institution overall remains predominately white. Moreover, as discussed in the above section on career mobility, the officers expressed the need for having Black officers in positions of power and influence within the police force. Increasing diversity and promoting inclusion from the top down was viewed as one of the most important factors in combating structural racism in the police force, and for ensuring that police officers can effectively carry out 
their duties when policing marginalized and racialized communities in Canada. It follows that since Canada is one of the most multi-cultural countries in the world, our police force must accurately reflect that diversity to ensure justice and fairness, both inside and outside the organization. As discussed by participant 1, the police force needs to see diversity at every level of the institution. He explains:

"What needs to be changed? Well you know arguably we need a more diverse organization at every level. At every level so that you have people in positions of authority, people that are in command positions that can sort of ensure that things are done in a fair way and you need people in a position to change policies that are wrong, but then there has to be a will. ... It takes time, it takes you know, you have to be able to change the hierarchy and the minds of certain people and it's a hell of a task. People are keeping to themselves and they don't want to learn about each other and they don't want to sort of you know interact with one another, it's hard to say."

Participant 1, April 2017

Participant 1 aptly notes that the biggest obstacle in changing the social hierarchy of the police force is to change the minds of people with influence, which is a difficult task. Given that the police officers who he works with tend to keep to themselves, the inter-racial interaction amongst his co-workers is limited. What needs to change is more social interaction across the organization to increase and promote inclusion and diversity. In a similar regard, participant 2 also notes that the lack of diversity is a major issue that must be addressed. This participant cites the fact that we need more police officers representing the diversity we see in Canada:

"We need to take into consideration the culture and language that the Black officer brings to the organization. For example, an officer from Nigeria or Ethiopia comes here with a culture and language that should be counted for an additional percentage points because it should not just be about the test for scores that determines who gets hired. It should also be about where a person is coming from and how their experiences can be helpful working in diverse communities that we serve in the country of Canada. Because we will come across people who speak different languages, and we will have to utilize our bilingual languages." Not just language, but having a more diverse police force means white officers can look to Black officers for support when dealing with Black communities that they may not have a lot of experience working with or understanding of.

Participant 2, May 2017 
As participant 2 explains, the strength of a Black officer is the difference in perspective, culture and language that they bring to the profession. Hiring more police officers from various ethnic communities is imperative to policing the racially diverse communities in Canada. Having a police force that speaks a variety of languages and is constituted by various ethnic groups is an invaluable resource, especially in crisis situations where the need for clear communication and understanding can be a matter of life or death. A police officer that can speak different languages, especially in a hostile scenario, can be better prepared to de-escalate a situation while gathering important facts quickly and efficiently. For this reason, an important recommendation for the future is to promote diversity and inclusion efforts within the police force by hiring more police officers that come from various cultural backgrounds, have varying life experiences, and speak different languages, but also giving them opportunities to be supervisors and be a part of the decision making processes. While my research above notes the pressure experienced by police officers to assimilate, the key messaging that needs to be communicated within the police force is that when it comes to good policing, strength lies in difference and diversity.

Participant 4 also noted that having a more diverse police force is necessary but stressed the fact that we need Black officers in positions with decision making power. He states that merely having more police officers that are Black was a solution in the 1960s, however, now in 2017 we need to extend ourselves beyond mere numbers of Black officers and look substantively to the authorities and positions these Black officers occupy. Participant 4 explains:

"I think we should have people from different communities and different cultures to reflect the communities that you police. However, this call that we need more Black police officers is a 1969 solution for a 2017 problem. What you need now is more Black supervisors who can call the shots in the communities. Not have to go back and report to the people that caused the problem in the first place."

Participant 4, May 2017 
Speaking directly to the point of placing decision making power in the hands of Black officers, participant 2 explains:

"In order for the Black community to have a true appreciation that the police are trying to change their attitude within the department, is that they have to see that change within the upper ranks. It can't only be a frontline guy that's showing up that looks like them because they know that most of the decisions do not lie with that individual. The decisionmaking powers are higher up the ranks and if they know that rank structure never changes, there will never be a fortified belief that the police are committed to change.

Participant 2, May 2017

It appears from both accounts that Black police officers note that merely having more Black officers is not going to be enough to impact meaningful change. Instead, we need to strive to have more Black officers in positions of influence. This means that encouraging the career advancement of Black officers is a key point. As discussed earlier in this paper, the participants have expressed their concerns regarding the fact that Black officers are passed up for promotion, do not receive proper training, and have more trouble 'fitting in' relative to their white counterparts. A solution to this issue is to ensure that we satisfy proportionality quotas with respect to positions of power and influence in the police force. The police institution must be subject to standards that they must have a representative police board of directors, executives and higher ranked police officers that are not only from various ethnic backgrounds, but that come directly from Black communities.

The second main proposition for change raised by the participants was the need for police officers to have more empathy for marginalized communities. The Black police officers noted that there must be a degree of understanding that police officers must have when they approach conflict in Black communities. Rather than escalating a situation and responding with excessive force, police officers must appreciate the unique tensions and issues that Black communities face. To truly become empathic and understanding of the social issues that Black individuals 
face in their daily lives, police officers must become educated on the historical violence and oppression experienced by this vulnerable population. As participant 3 explains:

"I think that there has to be a degree of empathy for mistakes. Even a dog knows the difference between being kicked and being tripped over. There has to be an education on both sides. I educate people on the use of force because a lot of people are not familiar with violence or violence where there is accountability and therefore a lot of the community is not attuned to the fact that there are times when you have to use violence and sometimes deadly force. A lot of the police community are not attuned to the fact that because Black people have been subjected to police brutality through decades that there may be a resentment. But the difference is the police officer took the oath, the community didn't take the oath, so the onus is on the police officers to minimize the conflict. It is not on the community. The community has a moral and ethical obligation to minimize the conflict but the police have the legal obligation because they took the oath."

Participant 3, May, 2017

To clarify, the 'oath' discussed by the above participant refers to the 'Oaths and Affirmations' that a police officer must take before they are sworn in for service. The police officer oath includes a commitment to uphold fundamental human rights, and to faithfully and impartially advance the interests of the public. The significance of this oath is that it places police officers to a high standard to carry out their duties faithfully and impartially (Police Services Act, 2010). This participant stresses the importance of police accountability, and placing the onus on the police officer to be understanding, and appreciate the social and historical context in which crisis situations often arise in Black communities. This Black officer notes that when faced with hostile attitudes, police officers must realize that the resentment and suspicion from Black communities against the police force is cultivated through years of oppression and discrimination. Instead of increasing conflict when faced with negative attitudes, the police have the moral and professional obligation to respond with empathy and understanding in an effort to minimize hostility and carry out their duties effectively. As the next section will discuss, the participant offers his opinion that promoting empathy can be achieved 
through formalized learning and education in the police force and would be a key and necessary step in dispelling negative social stereotypes, combating racism, and achieving equality.

In explaining that formal education and training is necessary in moving toward a progressive police force, participant 4 stresses the need for cultural sensitivity training, but also notes that while you can require formal training, you cannot train heart (or empathy). Participant 4 states:

"Through education and through learning more about others cultures, that's always a positive thing to go towards understanding another culture. A learning education is very strong, but it's there is a willingness that is required to be there. You can't train heart, we can't train willingness, regardless of what we do, we cannot control someone's will to be fair or to be objective. We can't train that regardless because education on its own has nothing to do with someone's compassion in doing something and how they do and how they act towards the communities they serve."

Participant 4, May 2017

This participant notes the value of ensuring that police officers are properly trained, yet also mentions that in order for this training to be impactful and effective, the police officers must have their 'heart' into it, meaning they are committed to learning. This participant aptly observes the inherent limitations of cultural and sensitivity training. While the content of such training programs may be commendable in that they encourage inclusion and diversity, the limit resides in the fact that the trainees must be receptive and willing to learn. Moreover, programs like cultural and sensitivity training may be perceived as no more than 'lip-service,' a tool to make it appear that organizations believe in diversity in policy, yet in practice, racist attitudes continue to persist. This means that we need to ensure we are hiring police officers that are dedicated to serving and protecting the community. In other words, this problem extends beyond the solution of mere training; instead, the real change must occur before police officers are hired. The police force should therefore be hiring police officers that are emphatic, compassionate and committed to the communities they serve. 


\section{CHAPTER 6: IMPLICATIONS AND CONCLUSION}

The focus of this essay was to examine the unique perspective of Black male police officers previously or currently employed in Canada. The inspiration for this topic comes from increasing social and political conflict between Black minority communities and the police. One must only look to the news media to gain a glimpse of the current socio-political struggles experienced in Black communities. Wortley (2011) argues that Black youth (age 15 - 29) are nine (9) times more likely to experience physical violence at the hands of law enforcement than their white counterparts. Given the modern day reality of these statistics, and my own personal experience of living in a young Black body, I sought to focus my research on highlighting the issues facing Black communities today. In specific, I employed critical race theory as a theoretical framework for my research and to offer context for my findings.

The goal of my research is to assist in deconstructing power structures within the police force by better understanding the social experiences of Black officers in Canada. By offering insight into the perspectives of Black police officers that have served the police force for many years, this paper highlights the personal thoughts and reflections that are otherwise silenced. I wanted to use my research as a platform to assist racialized individuals in sharing their experiences, mobilizing their stories, and empowering the marginalized Black community to give them a voice. Critical race theorists stress the importance of having Black communities share and talk about their experiences as racialized individuals to help combat structural racism.

Through conducting personal interviews with four police officers, I gained first hand insight on the unique problems that these Black police officers face in their professional lives

and their resilience and strength. My interviews lasted approximately one to two hours each. All interviews were conducted in person and were recorded and transcribed. After evaluating and 
analyzing my interview research findings, I derived four overarching themes. First, I found that all my interview participants expressed concerns regarding their career advancement and occupational mobility. The Black officers I interviewed were personally passed over for promotions without being provided an explanation, not hired for certain jobs within the police force without having their resumes reviewed, and highlighted issues with not being trained properly and having a high supervisor turnover rate. A second major theme I found was the external pressures faced by Black male officers who were not being accepted in their Black communities or the policing culture. As evidenced by the backlash in the Black community as well as the racist attitudes held within the police force, Black police officers somtimes experience multi-layered barriers of exclusion in both communities they are a part of.

The third major finding arising from my research findings is the fact that negative social stereotypes about Black communities and prejudicial attitudes were prevalent among the police force. In this regard, Black officers experienced high rates of discrimination and structural racism by their white officer colleagues. Some of the Black police officers I interviewed mentioned the pressure to conform to the white police culture by rejecting their own Blackness. This meant making Black jokes and being tougher on the Black individuals when carrying out their policing duties. In this regard, negative social stereotypes not only impacted Black communities generally, but had specific impacts on Black police officers who felt the need to reject their own culture by reinforcing stereotypes of their own people.

A fourth important theme that arose from my discussions related to making a change and future recommendations. All the police officers I interviewed expressed a sense of optimism and resilience in the face of the obstacles they experienced. An important way to effect change was to increase diversity and inclusion efforts within the police force by not only hiring more Black 
officers, but ensuring that Black officers occupy positions of power and influence. Moreover, cultural sensitivity training was mentioned as an important tool to assist current police officers with greater empathy and understanding of the communities they police. Lastly, rigorously screening police officers for bias and prejudice prior to hiring could be another method to combat the inherent racism within the police force. While these solutions separately are likely to create little change, using these strategies in tandem, while educating and training police officers could be long term solution to a fairer administration of justice.

In response to limiting police bias and racist attitudes held by officers, a possible solution can be to vigorously train and change the attitudes of current police officers and ensure that going forward the right police officers are hired. To ensure that appropriate police officers with good character are being hired, we would require more intense background checks to test the existing cultural awareness of incoming officers. A way to do this would be to require that police officers have sufficient volunteer experience and exposure working with visible minority populations. Moreover, incoming police officers should be interviewed on their commitment to mandatory ongoing learning throughout their careers.

During the recruitment process police officers should be assessed for racial bias. Screening for bias can be achieved by conducting interviews that examine inherent biases, or interview police officers with case study scenarios regarding racially sensitive topics to see how they would react and respond. While it is still possible that police officers will be able to pass such evaluations while retaining their prejudice, increasing focus on racial bias before hiring could be just one way to reduce racism in the police force.

As will be discussed in the following section regarding the implications of my research findings, the intention of my paper was to examine the views, perceptions and feelings of Black 
male police officers and understand the essence of their experiences. I seek to contribute to the existing critical race theorist literature, and to offer up viable solutions that can help a more just and fair administration of justice. As my research conclusions find, the major issues that Black police officers face are: the lack of career mobility and obstacles to career advancement, intense negative social stereotyping, both due to their occupational identity and racial identity as Black males, and the internal identity struggle of not being able to fully fit in within the Black community or within their professional policing community. The following section will discuss the implications of these problems, and seek to provide next best steps to respond to such issues.

\section{Implications for Social Work}

As a social worker, it is important to frame my research study within the context of implications for social work. The purpose of my research is not merely to identify problems, but rather, my goal for this study is to present solutions and future recommendations for the current socio-political issues that Black police officers experience on the job. My work can be understood based in the goals of community social work. A necessary skill of community social work involves understanding the power dynamics and social relations that govern the relationships between the policing institution and racialized communities and working to achieve social justice through structural change (Hall, 2017). In this regard, my research has helped to understand the essence of the experiences of four Black police officers in Canada. If we do not act as social workers, society runs the risk of having the current problems experienced by marginalized and disenfranchised groups increase and proliferates. The work we do as social workers, and the research we perform is vital to assist real change at ground level to policy and legislative reform. In the case at hand, not having the benefit of a social worker to help address 
the troubles faced by Black police officers, the realities experienced by this group will continue to go unnoticed and ignored.

Moreover, and from a community perspective, my role as a social worker is to conduct research and share information with the identified community of interest (Hall, 2017). The aim of generating research knowledge is therefore to formulate next best steps needed in developing a strategy to remedy the problems faced by the minority community of Black police officers in Canada. In turn, conducting this field research has allowed me to learn from the people in my community, in an effort to enhance collaboration and partnerships that lead to achieving real social change. The goal of my research is to allow my interview participants a chance to speak candidly about their experience at work, their goals, dreams and desires when it comes to their profession and their visions for the future. Through this dialogue and communication of shared experiences my research sought to address the problems of structural racism, combating negative racial stereotypes, and the need for more police training.

Identifying the fact that all of my interview participants noted the need for greater career advancement is a step toward requiring the police force to ensure that Black police officers occupy positions of power. I hope that my research will be used by policy makers and think-tank group organizations to compel the police force to increase their quotas on having Black officers in high ranking and decision making positions. Moreover, by identifying the persistent problem of structural racism in the police force, with respect to prejudicial attitudes and negative stereotypes, I hope my research will be used to improve the hiring and promotion practices of the police force and allow Black male officers better career mobility.

While I recognize that my research examined exclusively Black male officers, it is important to understand the experiences of Black women and LGBTQ community members to 
glean insight into diverse perspectives. The benefit of examining diverse and intersectional viewpoints, even within the Black community will offer a more comprehensive and thorough analysis of the systemic and inherent problems within the police force. My research has pointed out a lot of observations regarding the specific problems of Black officers, and attempted to offer solutions to these issues, but there remain unanswered questions. The first and most obvious question is: "How can we tell the story so that we are heard?" What I mean is that since the police force is predominately made up of white male police officers, we must communicate the problems experienced by Black officers in a way that the people in power and influence will listen. What we don't know of course, is, will they ever listen? Regardless of the specific outcome, the most important answer in the face of this uncertainty is, if we don't try, we will never know. 


\section{APPENDIX A. VERBAL RECRUITMENT SCRIPT}

The topic of my research paper is, In Their Shoes: Exploring the Social Experiences of Black Male Police Officers in Canada.

Two research questions guide this study

1) How do black police officers feel about members of their own racial or ethnic group being killed by the police? The tension I seek to explore is the inherent tension that black officers face when members of the police force are disproportionately killing members of their own race.

2) Do they experience racism within the police force?

I intend to interview several black male police officers in Ontario. In interviewing this demographic, I hope to uncover important perspectives of how black police officers have seen their practice of policing and how it has been shaped by the policing institution.

If you know any black male police officers who may be interested in the study, please have them contact me for more information.

First Name:

$$
\text { Anthony }
$$

School of Social Work

Dept/Office:

Institution:

$$
\text { Ryerson University }
$$

Last Name:

Email:

\section{Telephone:}

Lawrence

Anthony.lawrence@ryerson.ca

$647-880-8033$

\section{Academic Title:}

$$
\text { Graduate Student }
$$

Thank you for getting in contact with police officers that may be interested in the study. 


\section{APPENDIX B. INTERVIEW GUIDE}

In Their Shoes: Exploring the Social Experiences of Black Male Police Officers in Canada.

These are some of the questions that may be asked during the interview. If there are any questions that you are not comfortable answering you do not have to answer.

\section{Career}

- What made you choose policing as a career?

- Probing question: did anyone influence you to become a police officer.

- Did you hear anything about what it was like to be a black officer in Canada before you became a police officer.

- Probing question: If yes, how did this influence your decision to choose this career?

A day in a police officer's shoes.

- What is a typical day of a police officer?

- Probing questions: How does a typical conversation go with some of your colleagues?

- What are common scenarios that you experience on the job.

Race and policing

- Are there challenges being a black male police officer?

- Probing question: What are your relationships like with black communities?

- Racial profiling within the police is a topic that frequently comes up. What is your understanding of this sensitive issue?

- Probing question: Do you feel this plays out with violence and excessive use of force toward black people? If so, can you give me an example of what this would look like.

- Do you feel that some officers negatively stereotype blacks?

- Do you feel that there is racism within policing institutions?

- Probing question: Do you experience this from your colleagues and supervisors.

- Can you give me a specific example?

- Do you hear this in the conversations that officers have about black people?

- How do you feel when you see a black man or women being shot by the police and it is captured on video? (e.g., a video of an unarmed black man being shot in the back).

- Probing question: Do you think that this is a result of racial bias or hate toward blacks. 
- Do you think that some police fear black people? If so, do you think that this fear makes them quick to shoot black people rather than deescalating the situation?

- If so, can you give me an example of something they may have said or done to demonstrate this fear toward black people?

Identity

- Being a black male police officer you belong to both the police force and are a member of visible minority communities. What does this feel like for you? Do you feel internal conflict as your racial identity is perceived to be at odds with your occupational and professional identity?

- Probing question: If so, can you elaborate on this because you see what is being done to your community, but you work for the system that is harming your community?

\section{Police sub culture}

- Do you feel there are specific problems within the police sub culture that need to be addressed pertaining to race and policing?

- Probing questions: Do you feel that you are treated the same as white police officers?

Do you feel more black police officers need to be hired?

- Do you feel that the black police officers have their own community within the police sub culture?

\section{Closing questions}

- Before we conclude, is there anything else that you would like to discuss or, anything important that you want to mention? 


\author{
APPENDIX C. CONSENT FORM \\ SCHOOL OF SOCIAL WORK \\ FACULTY OF COMMUNITY SERVICES \\ Accredited by the Canadian Association of Schools of Social Work
}

\title{
Consent Agreement
}

You are being invited to participate in a research study. Please read this consent form so that you understand what your participation will involve. Before you consent to participate, please ask any questions to be sure you understand what your participation will involve.

Study: Race and Policing: Exploring the Social Experiences of Black male police Officers in Canada.

\section{INVESTIGATORS:}

This research study is being conducted by Anthony Lawrence, School of Social Work, Social Work student. The supervisor of this research study is Gordon Pon, MSW, PhD at Ryerson University.

If you have any questions or concerns about the research, please feel free to contact, Anthony Lawrence, 350 Victoria Street, Toronto, ON M5B2K3, 416-979-5000, Anthony.lawrence@Ryerson.ca Or you may contact Gordon Pon at 416-979-5000, ext. 4786, g2pon@ryerson.ca

\section{PURPOSE OF THE STUDY:}

This study is designed to explore the experiences of black male police officers in Canada. Three research questions guide this research:

1) How do black police officers feel about members of their own racial or ethnic group being killed by the police?

3) Do they experience racism within the policing institution?

I am completing this research to complete my major research paper requirement of my Master of Social Work degree. The results will contribute to my major research paper.

There will be 3-4 research participants being recruited for this study. The eligibility requirements to identify prospective participants are: The research participants must have been employed by a police institution in Ontario, (currently or previously), the research participants must be male and the research participants must be Black (who identify as African, Caribbean, American, or Canadian). Those who are ineligible for the study are individuals who are not Black and research participants who are not males. 
WHAT YOU WILL BE ASKED TO DO:

If you volunteer to participate in this study, you will be asked to do the following things:

\section{CONSENT FORM}

1) Sign the Ryerson University consent form. Take the time to read this form and ask questions about anything that you do not understand. I will also be reviewing this consent form with you. After you have read the consent form and if you accept to be a participant in the study, please sign the areas requiring your signature.

\section{ARRANGE A TIME TO MEET}

2) The research participant and Anthony Lawrence the researcher will arrange a time to meet for the interview. The interview can take place at Ryerson University in a private room that is secured with aural and visual privacy to ensure confidentiality. This is especially important due to the sensitivity of the information that may come up in the interview. You also have the option to choose a location that you would like to meet other than Ryerson University. The preferred location should be in a secured place with aural and visual privacy to ensure confidentiality. Public areas like coffee shops will not be used for interviews due to the sensitive nature of the research topic.

\section{REVIEW INTERVIEW GUIDE}

3) Review the interview guide prior to meeting the researcher for the interview. Take the time to read the interview guide to see what kinds of questions are going to be asked during the interview. If you have any concerns with the interview questions, this would be a good time to address them with the researcher.

Two sample research questions are: Racial profiling within the police is a topic that frequently comes up, especially in regard to Canadians of African descent. What is your understanding of this sensitive issue? What are some of the challenges of being a black male police officer?

\section{MEET FOR THE INTERVIEW}

4) Meet with the researcher at the agreed interview time. Interviews will last between 1 to 2 hours in length. There will only be one interview for this research study.

\section{REVIEW TRANSCRIPTION}

5) Once the researcher transcribes the interview you will have an opportunity to read the transcription if you would like to. Once you approve the researcher to move forward the researcher will proceed to complete the research paper. This can be sent to you through email or mailed to your preferred address. 


\section{APPROVE FINAL RESEARCH PAPER}

6) Before the final research paper is submitted to Ryerson University School of Social Work, you will have the opportunity to read the research paper to ensure you are okay with the way that your interview has been presented in the study and to ensure that there is no way that you can be identified in the study.

\section{POTENTIAL BENEFITS:}

I cannot guarantee that you will receive any benefits from participating in this study. However, this study aims to bring light to the experiences and feelings of racialized police officers

\section{WHAT ARE THE POTENTIAL RISKS TO YOU AS A PARTICIPANT:}

Psychological risk (e.g. feeling anxious, upset or uncomfortable)

Questions and topics that come up during interviews about your experiences as police officers may be triggering for you and make you feel anxious, upset or uncomfortable as sensitive topics are being discussed. The risk of this happening is low/minimal. A community resource sheet will be provided at the end of the interviews for officers who feel they would like some support after the interview. If any questions make you uncomfortable you can skip those questions and you can stop participation in the interview at any time.

\section{CONFIDENTIALITY:}

Everything pertaining to the study will be kept confidential and all transcriptions will be kept in a password protected file. All participant names will be pseudonyms unless participants request to use their real names. Participants will be reminded about confidentiality before and after interviews to ensure they understand that their names will not be used in the study. They will be advised that if they have any questions or concerns that they can contact the researcher at anytime. No personal information of identity will ever be included in the completed research publication. Participants will be asked to review/edit their interview transcripts as well as approve the final research paper to ensure they are comfortable that the information does not identify them to potential readers.

Information in this study will not be released to any other party for any reason. The audio recordings and interview transcriptions will be kept in secured file on a computer in the researcher's home that only the researcher has access to. These files will be password protected in addition to the password needed to be able to log onto the computer. These files will remain on the researcher's computer until the final draft of the major research paper is complete (estimated completion August 2017). Once the final draft is submitted to school of social work all files and transcriptions will be deleted from the computer and deleted a second time if they are put in the recycling bin. The audio files will be deleted once the transcriptions have been complete. I anticipate completing the transcriptions within two weeks of each interview. The transcriptions / data need to be kept until the final paper is submitted for me to go back and make necessary changes with the information. It also gives research participants the opportunity to 
listen to the audio and review their transcription anytime they would like to during the study. As a research participant, you have the right to review the audio and transcriptions of interviews anytime that you would like. The transcriptions are only kept until the final publication for my being able to review them and write my paper. Estimated completion date is August, 2017.

\section{PARTICIPATION:}

As a research participate you will not be paid to participate in this study

\section{COSTS TO PARTICIPATION:}

If interviews are held at Ryerson University, there will be parking costs. You will be reimbursed of these costs the day of the interview.

\section{COMPENSATION FOR INJURY:}

By agreeing to participate in this research, you are not giving up or waiving any legal right in the event that you are harmed during the research.

\section{VOLUNTARY PARTICIPATION AND WITHDRAWAL:}

As a research participant, your participation is entirely voluntary. As a research participant, you have the right to remove yourself from the study at any time and you have no obligation to complete it. Withdrawal from the study will not influence future relations with the researcher Anthony Lawrence or Ryerson University. You have the right to remove yourself from the research at any time and you have the right to request that your interview be destroyed and not used in the study. During the interview, you have the right to refuse to answer any questions that you do not want to discuss or which makes you uncomfortable.

\section{QUESTIONS ABOUT THE STUDY:}

If you have any questions about the research now, please ask. If you have questions later about the research, you may contact. Anthony Lawrence, Social Worker, 350 Victoria Street, Toronto, Ontario M5B 2K3, 416-979-5000, Anthony.lawrence@ ryerson.ca, or Gordon Pon, research supervisor MSW, PhD, 416-979-5000, ext. 4786, g2pon@ryerson.ca

This study has been reviewed by the Ryerson University Research Ethics Board. If you have questions regarding your rights as a participant in this study please contact:

Research Ethics Board c/o Office of the Vice President, Research and Innovation Ryerson University 350 Victoria Street Toronto, ON M5B 2K3 416-979-5042, rebchair@ryerson.ca 


\section{[Race and Policing: The Social Experiences Black Male Police Officers in Canada] \\ CONFIRMATION OF AGREEMENT:}

Your signature below indicates that you have read the information in this agreement and have had a chance to ask any questions you have about the study. Your signature also indicates that you agree to participate in the study and have been told that you can change your mind and withdraw your consent to participate at any time. You have been given a copy of this agreement. You have been told that by signing this consent agreement you are not giving up any of your legal rights.

Name of Participant (please print)

Signature of Participant

Date

\section{PSEUDONYM FOR NAME}

Your signature below indicates that at no time do you want your name to be used in the study and a pseudonym will be used instead.

Name of Participant (please print)

Signature of Participant

Date

\section{AUDIO-RECORDED}

I agree to be audio-recorded for the purposes of this study. I understand how these recordings will be stored and destroyed and only the researcher will have access to them. 


\section{APPENDIX D. POST INTERVIEW RESOURCE SHEET}

Mental health support

1) Mental health helpline, 1-866-531-2600 - toll free (Ontario)

2) Distress Lines 1-800-567-9699 - toll free (Ontario)

3) Canadian Mental Health Association 1-800-875-6213 - toll free (Ontario).

4) Centre for Addiction and Mental Health - toll free (1-800-463-6273) 


\section{References}

Ahmed, S. (2000). Strange encounters: Embodied others in post-coloniality (1st ed). New York: Routledge.

Ahmed, S. (2007). A phenomenology of whiteness. Feminist Theory, 8(2), 149-168.

Atkinson, R., \& Flint, J. (2001). Accessing hidden and hard-to-reach populations: Snowball research strategies. Sociology at Surrey. Retrieved 29 June 2017, from http://sru.soc.surrey.ac.uk/SRU33.pdf

Aylward, C. (1999). Canadian critical race theory: Racism and the law (1st ed). Halifax, N. Fernwood Pub.

Bailey, C. (2008). A guide to qualitative field research (1st ed). Thousand Oaks, Calif: Pine Forge Press.

Bonilla Silva, E. (2001). White supremacy and racism in the post-civil rights era (1st ed). Boulder: Lynne Rienner.

Bonilla-Silva, E. (2003). Racism without racists (1st ed). Lanham, Md.: Rowman \& Littlefield.

Brewer, R., \& Heitzeg, N. (2008). The racialization of crime and punishment: Criminal justice, color-blind racism, and the political economy of the prison industrial complex. American Behavioral Scientist, 51(5), 625-644. 
Brown, M. (1981). Working the street: Police discretion and the dilemmas of reform. The American Review of Public Administration, 15(3), 170.

Campbell, E. (2014). Using critical race theory to measure "racial competency" among social workers. Journal of Sociology and Social Work, 2(2), 75. http://dx.doi.org/10.15640/jssw.v2n2a5

Carmichael, J., \& Kent, S. (2014). The use of lethal force by Canadian police officers: Assessing the influence of female police officers and minority threat explanations on police shootings across large cities. American Journal of Criminal Justice, 40(4), 703-721.

Chase, S. (2003). Learning to listen: Narrative principles in a qualitative research methods course. 92-96.

Claire, M., \& Denis, J. (2014). Sociology of Racism. Retrieved 7 October 2016, from https://scholar.harvard.edu/files/matthewclair/files/sociology_of_racism_clairandenis_2015. pdf

Crenshaw, K. (1991). Mapping the margins: Intersectionality, identity politics, and violence against women of color. Stanford Law Review, 43(6), 1241. http://dx.doi.org/10.2307/1229039

De Chesnay, M. (2014). Nursing research using phenomenology: Qualitative designs and methods in nursing (1st ed.). New York: Springer Publishing Company. 
Delgado, R. (2000). Explaining the rise and fall of African American fortunes interest convergence and civil rights gains. In M. Dudziak (Ed.), Cold war civil rights: Race and the image of American democracy (1st ed). Princeton: Princeton University Press.

Delgado, R., \& Stefancic, J. (2000). Critical race theory: Tthe cutting edge (1st ed). Philadelphia: Temple University Press.

Du Bois, W. (1994). The Souls of Black Folk (1st ed.). New York: Dover Publications.

Dudovskiy, J. (2016). The ultimate guide to writing a dissertation in business studies: A step-bystep assistance (1st ed.). Pittsburgh: ResearchMethodology.net.

Doane, A. \& Bonilla-Silva, E. (2003). White out: The continuing significance of racism (1st ed., pp). New York: Routledge.

Gelling, L. (2015). Qualitative research. Nursing Standard, 29(30), 43-47.

Gillis, W. (2015). How many black men have been killed by Toronto police? We can't know. The Toronto Star. Retrieved from https://www.thestar.com/news/crime/2015/08/16/howmany-black-men-have-been-killed-by-toronto-police-we-cant-know.html

Gould, L. (2000). A longitudinal approach to the study of the police personality: Race/gender differences. Journal of Police and Criminal Psychology, 15(2), 41-51.

Grieve, J., \& French, J. (2000). Does institutional racism exist in the metropolitan police service? In D. Green, J. French, M. Ignatieff, M. O'Brien, \& R. Skidelsky (Eds.), Institutional 
racism and the police: Fact or fiction? (1st ed.). London: The Institute for the Study of Civil Society. Retrieved from http://www.civitas.org.uk/pdf/cs06.pdf

Hall, C. (2017). Social work practice in community development |Canadian Association of Social Workers. Casw-acts.ca. Retrieved 30 May 2017, from http://www.casw-acts.ca/en/socialwork-practice-community-development

Ibe, P., Ochie, C., \& Obiyan, E. (2012). Racial misuse of criminal profiling by law Enforcement: Intentions and implications. African Journal of Criminology and Justice Studies, 6(2), 177195.

Jaccoud, M., \& Felices, M. (1999). Ethnicization of the police in Canada. Canadian Journal of Law and Society, 14(01), 83-100.

Jain, H., Singh, P., \& Agocs, C. (2000). Recruitment, selection and promotion of visibleminority and aboriginal police officers in selected Canadian police services. Canadian Public Administration/Administration Publique Du Canada, 43(1), 46-74.

James, L., James, S., \& Vila, B. (2016). The reverse racism effect. Criminology \& Public Policy, 15(2), 457-479.

Jayewardene, C., \& Talbot, C. (1990). Police recruitment of ethnic minorities. Ottawa: Canadian Police College.

Kelling, G. \& Coles, C. (1996). Fixing broken windows (1st ed). New York: Martin Kessler Books. 
Kennedy, R., \& Hansford, J. (2016). Thematic hearing on excessive use of force by the police against black Americans in the United States. New York: International Human Rights Law Clinic and Global Justice Clinic.

Lai, Y., \& Zhao, J. (2010). The impact of race/ethnicity, neighborhood context, and police/citizen interaction on residents' attitudes toward the police. Journal of Criminal Justice, 38(4), 685-692.

Lawrence, C. (1995). The id, the ego and equal protection: Reckoning with unconscious racism. In K. Crenshaw, Critical race theory: The key writings that formed the movement (1st ed.) New York: The New Press.

Maclellan, L. (2015). Toronto Police controversy: What is 'carding' and is it legal? Yahoo News. Retrieved from https://ca.news.yahoo.com/blogs/dailybrew/toronto-police-controversy-what-is--carding--and-is-it-legal-192840113.html

Micucci, A., \& Gomme, I. (2005). American police and subcultural support for the use of excessive force. Journal of Criminal Justice, 33(5), 487-500.

National Institute of Justice. (2001). Disorder in urban neighborhoods— does it lead to crime? Detroit: U.S. Department of Justice.

Nease, K., \& Kupfer, M. (2016). Witness describes fatal confrontation between Abdirahman Abdi and police. cbcnews. Retrieved from http://www.cbc.ca/news/canada/ottawa/witnessconfrontation-abdirahman-abdi-1.3695047 
Newton, N. (2010). The use of semi-structured interviews in qualitative research: Strengths and weaknesses. Exploring Qualitative Methods, 1(3), 1-11.

Novak, K., \& Chamlin, M. (2012). Racial threat, suspicion, and police behavior: The impact of race and place in traffic enforcement. Crime \& Delinquency, 58(2), 275-300.

O'Connor, C. (2008). Citizen attitudes toward the police in Canada. Policing: An International Journal of Police Strategies \& Management, 31(4), 578-595.

Pickler, R. (2011). Understanding phenomenological approaches to data analysis. Journal of Pediatric Health Care, 25(1), 67-71. http://dx.doi.org/10.1016/j.pedhc.2010.09.004

Pietkiewicz, I., \& Smith, J. (2012). A practical guide to using interpretative phenomenological analysis in qualitative research psychology. Czasopismo Psychologiczne Psychological Journal, 20(1), 1-8. http://dx.doi.org/10.14691/cppj.20.1.7

Police Services Act. (2010). Ontario.ca. Retrieved 29 June 2017, from https://www.ontario.ca/laws/regulation/910144/v1

Richardson, R. (2007). Black masculinity and the U.S. South: From uncle tom to gangsta (The new southern studies) (1st ed). City? University of Georgia.

Sewell, W., Horsford, C., Coleman, K., \& Watkins, C. (2016). Vile vigilance: An integrated theoretical framework for understanding the state of Black surveillance. Journal of Human Behavior in the Social Environment, 26(3-4), 287-302. 
Smith, B., \& Holmes, M. (2014). Police use of excessive force in minority communities: A test of the minority threat, place, and community accountability hypotheses. Social Problems, 61(1), 83-104.

Stuart, D., \& Tanovich, D. (2014). Criminal Reports (pp. 76-77). Toronto. Retrieved from https://poseidon01.ssrn.com/delivery.php?ID=5951181230020830880180941210700870680 52035058029030050009003085102005030011114071076118021122027111056019100018 00308710302111001508007800703411810909912407807806509308301709111509700009 $4087029121115024121113022098079123113024004070074004123127089121 \& \mathrm{EXT}=\mathrm{pdf}$

Thobani, S. (2007). Exalted subjects: Studies in the making of race and nation in Canada (1st ed.). Toronto: University of Toronto Press.

Volpp, L. (2002). The citizen and the terrorist. Berkeley Law Scholarship Repository, 23, 570. Retrieved from http://scholarship.law.berkeley.edu/cgi/viewcontent.cgi?article=1514\&context=facpubs

Wagner, B. (2009). Disturbing the peace. Cambridge, Mass.: Harvard University Press.

Walcott, R. (2003). Black like who? Writing black Canada. (1st ed). Toronto: Insomniac Press.

Williams, P. (1991). The alchemy of race and rights (1st ed.). Cambridge: Harvard University Press.

Wortley, S., \& Owusu-Bempah, A. (2011). The usual suspects: Police stop and search practices in Canada. Policing and Society, 21(4), 395-407. 